\title{
Glossa
}

a journal of general linguistics

\section{Mechanisms of productivity in word formation: Transitivity alternations in Japanese}

\section{CHISATO KITAGAWA (D)}

\section{] $\mathrm{u}[$ ubiquity press}

\section{Abstract}

The extensive system of Japanese transitivity alternations (TrAlt) has inspired a great number of noteworthy works. This paper, adopting the theoretical apparatus of the Strong Minimalist thesis and focusing on the "in-between voice" (i.e., between the idiosyncratic lexical and the morpho-syntactic) characteristics of the TrAlt, aims to explicate its productivity phenomena. The paper offers detailed and novel analyses of transitivity suffixes - ar (a lexical passive) and -e (which has sometimes been characterized as a "causative-passive" suffix), and delineates the mechanisms of productivity by closely examining the interactive functions of these two suffixes and the verbal roots (R's) that host them.

\section{CORRESPONDING AUTHOR:}

\section{Chisato Kitagawa}

University of Massachusetts Amherst, US

kitagawa@umass.edu

\section{KEYWORDS:}

causative-passive suffix; in-between voice; Japanese; lexical passive; new word creation; transitivity alternations

TO CITE THIS ARTICLE: Kitagawa, Chisato. 2021. Mechanisms of productivity in word formation: Transitivity alternations in Japanese. Glossa: a journal of general linguistics 6(1): 69. 1-24. DOI: https://doi.org/10.5334/ gjgl.1304 


\section{Introduction}

The extensive transitivity alternation system in Japanese (henceforth TrAlt) ${ }^{1}$ is represented by doublet pairs composed, in each case, of a verbal root (henceforth $\mathrm{R}$ ) and a transitivity suffix signaling the transitivity opposition. Its defining characteristic, as pointed out by Noda (1961:214), is its "in-between voice" status (tyuukan no voice in his words). ${ }^{2}$ The TrAlt represents the "in-between voice," because it operates somewhere between the truly idiosyncratic lexical formation expressing voice distinction and the syntactic operation involving (r)are direct passivization and periphrastic (s)ase causativization. This "in-between voice" characteristically manifests in seemingly contradictory phenomena in that, on one hand, the transitivity suffix that a particular R takes is "not predictable" (Hasegawa 2001: 2) but, on the other, the TrAlt also allows, as pointed out by Nishio (1954), Miyaji (1985), and Kageyama (1996), quite robust zoogo 'new word creation' (Kageyama 1996: 191) ("new" in the sense that the given formations are not registered in earlier dictionaries). ${ }^{3}$ In this respect, Japanese TrAlt presents a picture significantly different from the voice alternation systems of European languages discussed in Lavine and Babby (2019). It also is an issue not covered in the extensive cross-linguistic study of transitivity alternation by Alexiadou et al. (2015).

My objective is to delineate the mechanisms of this productivity, restricting my attention to the following three transitivity suffixes, - $\operatorname{ar}$ (henceforth $A R$ ), -as (henceforth $A S$ ), and - $e$ (henceforth E). ${ }^{4}$ To that end, I adopt the theoretical apparatus provided by the Strong Minimalist thesis of Chomsky (2013; 2015), especially in a way articulated in Epstein et al. (2016), ${ }^{5}$ in order to provide a novel explication of the precise functions of these "transitivity" suffixes, in particular $A R$ and $E$. The exact functions of these suffixes with respect to the productivity phenomena have never been sufficiently identified in the literature in spite of the fact that the TrAlt has been subject to intense studies for a long period of time. Without clarification of such matters, no study of Japanese TrAlt properly contributes to the cross-linguistic understanding of word formation involving voice alternations.

The outline of the paper is as follows. Section 2 provides the general characteristics of Japanese TrAlt. Section 3 offers detailed analyses of the two distinct ways in which suffix AR can manifest - either as "lexical passive" or as simple "intransitivizer." Section 4 discusses the productivity phenomena involving $A R$. Section 5 is a brief account of lexical causative $A S .^{6}$ In Section 6, I present a unified and novel analysis of multi-faceted manifestations of suffix $E$, highlighting its peculiar behavioral patterns intricately interacting with those of lexical passive

1 The range of TrAlt pairs is broader, for instance, than the corresponding system in English described in Levin and Rappaport Hovav (1995) (see Matsumoto 2016c: 54).

2 Cross-linguistically, "somewhere between lexicon and grammar" is a familiar issue involving causativization (e.g., Genee 2016; Muñoz 2016).

3 For example, an internet blog site, hiiragi-june 'holly-June' dated 2007-09-05, commented on a newly created transitive verb [tati.ag-E] 'start out (a project)' first appearing as a computer related new word (e.g., pasokon-o tati. ag-e 'start up a personal computer') formed on the basis of the already existing intransitive verb [tati.ag-AR] 'stand up, get up' by analogy to one of the doublet patterns in the TrAlt system (to be identified as Type (1C) $\left\{[\mathrm{R}-A R]_{\text {intr }} /\right.$ $\left.[R-E]_{\text {tr }}\right\}$ ). The use of [tati.ag-E $]_{\text {tr }}$ later expanded beyond the sphere of computer discourse: e.g., Venture kigyoo-o tati. $a g-E$ 'start up a venture enterprise'. The authoritative and conservative Japanese language dictionary Koojien listed this transitive tati.ag-E for the first time in its Fifth Edition published in November 1998 as a computer related word, and a more trend-sensitive Japanese language dictionary Iwanami Kokugo Jiten 'Iwanami Japanese Language Dictionary' listed it for the first time in its Fifth Edition published in November 1994. We will return to this "new word formation by analogy" issue in Section 7.

4 In this, I emulate Kageyama's (1996) practice. It is also instructive that Narrog (2016: 257), in his detailed diachronic study, cites these three as the representative formatives contributing to the TrAlt system.

5 This framework, as recognized by Epstein et al. (2016: 89), is similar to that of Marantz's Distributed Morphology; to quote Marantz (1997: 205):

"To imagine a theory in which the grammar constructs all words in the syntax by the same general mechanisms ("merge and move," see Chomsky 1995) that construct phrases, it is useful to make the natural assumption that whether you get a "zero-level category" (word-like unit) or a phrasal category by merging two constituents is a function of the constituents involved, not of the "merger" operation itself. That is, there is no reason not to build words in the syntax via "merger" (simple binary combination) as long as there are no special principles of composition that separate the combining of words into phrases from the combining of morphemes into words."

6 For the extensive analysis of $A S$ (along with that of $E$ and $A R$ ), see Matsumoto (2016c: 53), which presents a detailed study of the Japanese TrAlt, utilizing "a hierarchy of schemas such as those proposed in Booij (2007; 2010) in the framework of Construction Morphology," a theoretical framework quite different from that adopted by such authors as Comrie (2006), Haspelmath (1993), and Jacobsen (1992). Matsumoto's analysis unearths some intriguing, and hitherto unknown, phonological subregularity maintained in the Japanese TrAlt system. 
$A R$. The derivational directionality critically involved in new word creaton in the context of the Japanese TrAlt is addressed in Section 7. And, Section 8 addresses the issue of mechanisms of productivity operative in the context of Japanese TrAlt.

\section{Japanese transitivity alternation (TrAlt)}

TrAlt is a strikingly familiar phenomenon in Japanese. The following chart is based on Jacobsen's (1992: 258-268) "Appendix" which "contains all transitive and intransitive verbs falling into pairs which are listed in Kenkyuusha's New School Japanese-English Diectionary (1968)" with "some pairs added from Shimada 1979" (Jacobsen 1992: 269). ${ }^{7}$ In (1), the suffix pattern $\{X / Y\}$ indicates that, given the identical R, the R-X represents an $[R-X]_{\text {intr }}$ and the R-Y an $[R-Y]_{\text {tr' }}$ constituting thus a transitivity doublet pair. The symbol " $\varnothing$ ” stands for "phonological null."

\begin{tabular}{|c|c|c|c|c|}
\hline Type & Suffix Pattern & Intransitive, e.g. & Transitive, e.g. & \\
\hline (A) & $\{\varnothing / E\}$ & sizum 'sink ${ }_{\text {intr }}$ ' & sizum- 'sink $_{\mathrm{tr}}{ }^{\prime}$ & $34(38)$ \\
\hline (B) & $\{E / \varnothing\}$ & or-E 'break ${ }_{\text {intr }}$ ' & or 'break ${ }_{\mathrm{tr}}$ ' & $30(38)$ \\
\hline (C) & $\{A R / E\}$ & mag- $A R$ 'bend ${ }_{\text {intr }}$ & mag- $E$ 'bend ${ }_{\mathrm{tr}}$ & 70 (59) \\
\hline (D) & $\{E / A S\}$ & $k o g-E^{\prime b u r n}{ }_{\text {intr }}$ ' & kog-AS 'burn ${ }_{\mathrm{tr}}$ & $45(42)$ \\
\hline (E) & $\{A R / \varnothing\}$ & husag-AR 'get plugged' & husag 'plug' & $8(8)$ \\
\hline (F) & $\{\varnothing / A S\}$ & tir 'scatter ${ }_{\text {intr }}$ ' & tir- $A S$ 'scatter ${ }_{\text {tr }}$ ' & $38(31)$ \\
\hline
\end{tabular}

TrAlt is thus marked "by a series of verbal oppositions cutting across the native verb system" (Jacobsen 1992: 56); all participating verb pairs can be said to represent a changeable state of the subject/object, and therefore can be said to have "a theme or theme-like subject/object" (Matsumoto 2016: 53). This "opposition" is expressed by transitivity suffixes $A R, A S$, and $E$.

Following the spirit of Marantz (1984), I assume that those suffixes are variants of the category $v$, which, as noted by Pylkkänen (2008: 7), stands for any functional head that is of the verbal category. ${ }^{8}$ With Chomsky $(1995 ; 2013 ; 2015), v$ stands for the universal functional category directly involved in the building of predicates. For the purpose of this paper, I venture to depart somewhat from Chomsky's (2013: 43, fn. 29) specific characterization of $v$ that it has "(at least) two "flavors": $v$ for unaccusative/passive, $v^{*}$ for transitive/unergative. The reason for this departure is that Japanese is an agglutinative language. Of agglutination, Poppe (1965: 190) comments: "All Altaic languages are agglutinative in structure. Agglutinative means that inflection and word formation take place by adding suffixes to stems" (Poppe 1965: 180); "the suffixes are monofunctional, contrary to the polyfunctional endings of inflectional IndoEuropean languages." Accordingly, I claim that the Japanese $v$ suffixes $A R, A S$, and $E$ are all monofunctional. The purpose of this paper is thus to define the nature of the monofunctionality undertaken by each of these suffixes. In this scheme, such properties as unaccusativity or unergativity belong to the $\mathrm{R}$ categories. Translating Chomsky's above specification for the present paper, I would only assume that $v$ has "(at least) two flavors": $v$ for passive-orientation, and $v^{*}$ for transitive-orientation; I use " $v$ " hereafter as the representative term, however, unless the distinction becomes crucial in any given context. ${ }^{9}$ I presume that this $v$, merged to an $\mathrm{R}$, assigns a status of "word" to the resulting R- $v$ construct. ${ }^{10}$

The R- $v$ construct constitutes, to borrow Epstein et al's (2016: 98) phraseology, an "X0-level" amalgam "created by internal pair-Merge" (i.e. syntactic internal pair-Merge of R to $v$ ). In this

7 Chart (1) covers the major types of Jacobsen's (1992) “classification types" (except one), our Types (1A), (1B), (1C), (1D), (1E), and (1F) corresponding respectfully to his (II), (I), (III), (IX), (IV), and (VIII). The "numbers of pairs" cited without parentheses refer to the numbers given in Jacobsen's list of "core" (Jacobsen 2016: 23) intransitive - transitive pairs. The numbers in the parentheses are Matsumoto's (2016a) for the corresponding categories. For discussions on "non-core" verb pairs, see Matsumoto (2016b: 489). The one prominent type (i.e., Jacobsen's (V): e.g., kae-s 'return ' vs. kae-r 'return ${ }_{\text {intr }}$ '; 27 pairs), and those listed in his "minor" classes are not included in (1), and will not be discussed in this paper in order to focus on transitivity suffixes $A R, A S$, and $E$. For discussions on the omitted groups, see Jacobsen (1992), Kitagawa \& Fujii (1999), and Matsumoto (2016c), among others.

8 For related discussions concerning little $v$ pertaining to Japanese transitivity suffixes, see Volpe (2005) and Marantz (2013: 106-108) among others.

9 Epstein et al. (2016) state that $v^{*}$ fails to function as a phase head in the context of internal pair-Merge. Japanese $v$ suffixes follow their prediction. I refrain from any further discussion on this, however.

10 In this issue of "word" I depart from Epstein et al. (2016: 89), who seem to reserve the term "word formation" to the "presyntactic" morphology (i.e., their "external pair-Merge" operation). A case of external pair-Merge is briefly discussed in fn. 21 . 
manner, I put into effect a perspective entertained by such works as Mendivil-Giró (2019: 1162) that "words are not lexical units, but rather syntactic constructions produced by the computational system."

Japanese TrAlt is marked by the fact that the verbs that participate in TrAlt are by and large "basic" verbs (Hayatsu 1989: 250-53). ${ }^{11}$ It is perhaps for this reason that it has inspired a great number of memorable works - including Motoori (1828), Sakuma (1936), Jacobsen (1992), Suga \& Hayatsu (1995), Kageyama (1996), Miyagawa (1998), Matsumoto (2000a; 2000b; 2016c), and to name just a few. As noted by Sakuma, Okutsu, and many others, $v$ suffixes AR and $A S$ show strong affinities to syntactically active direct ( $r$ )are passive and periphrastic ( $s$ ) ase causative, respectively, in regard to their lexical (having to do with the surface presence or absence of the external argument) and functional (relating to [+/-ACC]) properties. We begin in the next section with our investigation of $A R$.

\section{AR}

One critical issue about $A R$ not yet addressed sufficiently is whether or not it is simple "intransitivizer" or "lexical passive." To pursue this issue, I will assume at the outset that Matsumoto (2000d: 175) is essentially correct in his claim that all AR's are associated with the functional feature [-ACC]. The question as to whether this feature manifests as simple intransitivizer or as a lexical passive which shows notable similarity to the syntactically active direct passive (r)are (Kuroda 1979) thus depends on the distinct idiosyncratic lexico-semantic properties of the R's that select AR's.

\section{1 "Lexical passive" vs. "Intransitivizer"}

Recall that only 8 pairs are listed in (1) for the R-AR constructs of Type (1E) $\{A R / \varnothing\}$. In this subsection I examine the R-AR constructs of Type (1E) $\{A R / \varnothing\}$ so as to examine the functional status of $A R$ with respect to the feature [-ACC]. ${ }^{12}$ The set of diagnostic questions given in (2) is employed to tease out the two distinct manifestations of $A R$ : "intransitivizer" or "lexical passive."

a. Does $A R$, like syntactically active direct passive ( $r$ are, promote the accusative marked NP to the subject position, demoting the agentive or triggering causer subject NP (originally case-marked nominative) to a non-subject position followed either by postposition $n i$ 'by' or niyotte 'by'? If yes, as in (3a; 3b) and (4a; $4 \mathrm{~b}$ ), the $A R$ functions as a "lexical passive." The structural representation of (3b) is given in (5).

b. Does the R-AR allow the retention of the subject NP with the nominative case marking intact, demoting at the same time the accusative-marked NP to resurface as a postpositional phrase (PP)? If yes, as in (6a; 6b) and (7a; 7b), the $A R$ functions as an intransitivizer. The structural representation of $(6 \mathrm{~b})$ is given in (8).

Which interpretation the $A R$ of a given Type (1E) R-AR construct would have is not predictable, being dependent on the idiosyncratic lexico-semantic property of the participating $R$. In the examples to be cited hereafter, $A R$ is simply identified in gloss as $A R$ whereas direct passive ( $r$ ) are is glossed as "PASSIVE."

11 Hayatsu (1989) reports that, of about 3,540 verbs contained in Kadokawa Ruigo Ziten [Kadokawa Thesaurus], 1,180 verbs are TrAlt doublets (i.e., 590 pairs, 33.3\%, including compound verbal expressions), and that those doublets tend to be basic common words (e.g., kir 'cut'), whereas those that do not participate in TrAlt tend to be verbs that express semantically more specific events (e.g., tat 'cut [cloth for dresses]', nag 'cut [with a long and curved blade]', kizam 'chop up'). On underspecification issues as a crosslinguistic factor, see Lavine and Babby (2019).

12 Of eight items listed by Jacobsen's Class IV (our Type 1E), I have discounted tamaw-\{AR/ $\varnothing\}$ 'give' and kurum$\{A R / \varnothing\}$ 'wrap' because the former, tamaw, is, in my view, too archaic and the latter, kurum, can also be understood as Type (1C) $\mathrm{R}-\{A R / E\}$ as it is one of those that can engage in triplet formation (involving Types $1 \mathrm{E}$ and $1 \mathrm{C}$ in this case). I have added, however, sas- $\{A R / \varnothing\}$ 'sting', not listed in Jacobsen's Class IV. 
a. Kuma-ga azarasi no ko-o tukam-ta. (tukam-ta $\rightarrow$ tukan-da) bear-NOM seal 's baby-ACC grab-PAST 'A bear grabbed a baby seal.'

b. Azarasi no ko-ga kuma-ni tukam-AT-ta. seal 's baby-NOM bear-by grab-AR-PAST

'A baby seal was caught by a bear.'

( $A R$ here is a lexical passive in accordance to (2a).)

c. Azarasi no ko-ga kuma-ni(yotte) tukam-are-ta. seal 's baby-NOM bear-by grab-PASSIVE-PAST

'A baby seal was grabbed by a bear.'

Lexical passive $A R$ :

a. Hutatu no hito.kage-ga Sue no kage-o hasan-da. ( $\leftarrow$ hasam-ta) two 's human.shadow-NOM $S$ 's shadow-ACC put.in.between-PAST 'Two human shadows encroached upon Sue's shadow from the sides.'

b. Sue no kage-ga hutatu no hitokage-ni(*yotte) hasam-AT-ta. $S$ 's shadow-NOM two 's shadow-by put.in.between-AR-PAST 'Sue's shadow was encroached upon by two human shadows from the sides.' ( $A R$ here is a lexical passive in accordance to (2a).)

c. Sue no kage-ga hutatu no hitokage-ni(yotte) hasam-are-ta. $S$ 's shadow-NOM two 's shadow-by put.inbetween-PASSIVE-PAST 'Sue's shadow was encroached upon by two human shadows from the sides.'

(5)

Lexical passive $A R$ :

$\left.\left.\left[_{\mathrm{TP}} k o_{\mathrm{i}} \ldots\left[_{\mathrm{vP}} t_{\mathrm{j} . . .}\left[\mathrm{pP} k u m a_{\mathrm{j}}-n i\right]_{\ldots}\left[{ }_{\mathrm{VP}} t_{\mathrm{i}}\left(t_{\mathrm{k}}\right)\right]\right]_{\left[_{v}\right.}<\operatorname{tukam}_{\mathrm{k}}, A R>\right]\right]\right]$

In (3b)/(5), a lexical passive $A R$ with [-ACC] internally pair-Merges to an $\mathrm{R}$ with the consequence that NP azarasi no ko 'baby seal' raises to the Spec of TP to receive the nominative case, with the agent kuma 'bear' retained in the postpositional ni 'by' phrase just as it happens with the ( $r$ ) are direct passive (3c). ${ }^{13}$ There is no licit construction where an AR occurs with $\mathrm{R}$ tukam 'grab' functioning as an intransitivizer.

Examples of $A R$ behaving as an intransitivizer are given below:

Intransitivizer $A R$ :

a. Dokubari-ga kare no kubi-o sasi-ta. poison.needle-NOM he 's neck-ACC stick-PAST 'A poisoned needle pierced his neck.'

b. Dokubari-ga kare no kubi-ni sas-AT-ta. poison.needle-NOM he 's neck-into stick-AR-PAST 'A poisoned needle stuck into his neck.' ( $A R$ here is an intransitivizer in accordance with (2b).)

c. Kare no kubi-ga dokubari-ni(yotte) sas- $\{* A T, \quad$ (r)are $\}$-ta. (sas-(r)are $\rightarrow$ sas-are) he 's neck-NOM poison.needle-by stick-\{*AR, PASSIVE\}-PAST

'His neck was pierced by a poisoned needle.'

(As marked, $A R$ here is not a lexical passive since it does not follow (2a).)

In (6) the well-formed (b) sentence shows that $A R$ here functions as an intransitivizer. In the passive context (c), sas-AR is illicit, while passive (r)are is fine, indicating further that the $A R$ in sas-AR functions only as an intransitivizer. The next example follows suit.

13 Epstein et al. (2016: 89) notes: "As for the formulation of Merge, there are two kinds: (i) set-Merge that takes $\mathrm{X}$ and $\mathrm{Y}$, and forms the two-membered set $\{\mathrm{X}, \mathrm{Y}\}$, and (ii) pair-Merge that takes $\mathrm{X}$ and $\mathrm{Y}$, and forms the ordered pair $<\mathrm{X}, \mathrm{Y}\rangle$. 
a. Kare-ga uzukumaru Kansin no senaka-o matai-da.

he-NOM crouching $\mathrm{K}$ 's back-ACC straddle-PAST

'He straddled crouching Kansin's back.'

b. Kare-ga uzukumaru Kansin no senaka-ni matag-AT-ta. he-NOM crouching $\mathrm{K}$ 's back-onto straddle-AR-PAST

'He straddled the back of crouching Kansin.'

( $A R$ here is an intransitivizer in accordance to (2b).)

c. Uzukumaru Kansin no senaka-ga kare-ni(yotte) matag- $\left\{{ }^{*} A T\right.$, (r)are $\}$-ta. crouching $\mathrm{K} \quad$ 's back-NOM he-by stralddle- $\{A R$, PASSIVE $\}$-PAST 'The back of crouching Kansin was straddled by him.'

( $A R$ here is not a lexical passive, since it does not follow (2a).)

(8)

Intransitivizer $A R$ :

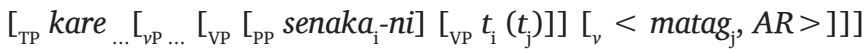

A given $\mathrm{R}$ participating in the Type (1E) doublet pattern must therefore be registered in its lexical entry with respect to these two factors: (i) its participation in Type (1E); and (ii) its idiosyncratic choice between the two possible interpretations of $A R$ (i.e., lexical passive or intransitivizer).

\subsection{Type (1C) $\{A R / E\} A R$ 's are lexical passives}

To determine whether or not the Type (1C) $\{A R / E\} A R$ functions as a lexical passive, we use the same diagnostic tests as in (2) reproduced here as (9).

a. Does $A R$, like syntactically active direct passive ( $r$ )are, promote the accusative marked NP to the subject position, demoting the agentive or triggering causer subject NP (originally case-marked nominative) to a non-subject position followed either by postposition $n i$ 'by' or niyotte 'by'? If yes, the $A R$ in question is a lexical passive.

b. Does the R-AR allow the retention of the subject NP with the nominative case marking intact, demoting at the same time the accusative-marked NP to resurface as a PP? If yes, the $A R$ is an intransitivizer.

The tests (9a) and (9b) reveal that the type (1C) $\{A R / E\} A R$ 's attached to the transitive R's are all variants of lexical passives, and not intransitivizers, as indicated by (10). Idiosyncratic variations such as (10a), (10b), and (10c) manifest depending on the co-occurring R's.

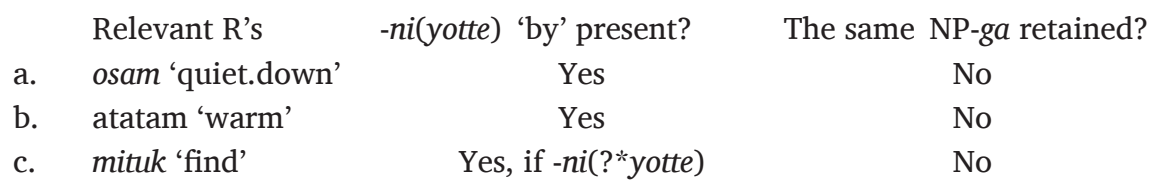

We know that the $A R^{\prime}$ 's in (10) are lexical passives because they all meet (9a) regarding the presence of -(ni)yotte 'by' and reject what (9b) prescribes. The AR's in the pattern (10a) are exemplified in (11), allowing niyotte 'by' and rejecting the retention of the subject NP with its (original) nominative case marking intact. Note the kind of similarity and non-similarity between the $A R$ and the direct passive (r)are.

a. $\{$ Kare, Yokisi-na-katta bakuhatu\}-ga sono sawagi-o osam-E-ta. $\{$ he, expect-not-PAST explosion $\}$-NOM that uproar-ACC suppress-E-PAST ' $\{$ He, The unexpected explosion $\}$ suppressed that disturbance.'

b. Sono sawagi-ga \{kare, yokisi-na-katta bakuhatu\}-niyotte osam-AT-ta. that uproar-NOM $\{$ he, expect-not-PAST explosion\}-by suppress-AR-PAST 'That disturbance was suppressed by $\{$ him, the unexpected explosion\}.' ( $A R$ here is lexical passive, satisfying (9a).) 
c. *\{Kare, Yokisi-na-katta bakuhatu $\}$-ga sono sawagi-ni osam-AT-ta. \{he, expect-not-PAST explosion\}-NOM that uproar-in regulate-AR-PAST (Intended: ' $\{\mathrm{He}$, The unexpected explosion $\}$ was suppressed by that disturbance.') (This sentence should have been fine if the $A R$ here were an intransitivizer, satisfying (9b). The fact that it is illicit shows that this $A R$ is a lexical passive.)

d. *Sono sawagi-ga \{kare, yokisi-na-katta bakuhatu\}-niyotte osam-are-ta. that uproar-NOM \{he, expect-not-PAST explosion\}-by pacify-PASSIVE-PAST (Intended: 'The disturbance was suppressed by \{him, the unexpected explosion\}.')

e. Sono sawagi-ga \{kare, *yokisi-na-katta bakuhatu\}-niyotte osam-E-rare-ta. that uproar-NOM he, expect-not-PAST explosion-by pacify- $E$-passive-PAST 'The disturbance was suppressed by $\{$ him, *the unexpected explosion\}.' (The fact that (11d) with passive (r)are directly attached to $\mathrm{R}$ is illicit, while (11e) in which it is attached to [R-E] is felicitous, shows that in the context of Type (1C) the syntactically active passive ( $r$ )are cannot directly attach to an R).

Example (11b) with lexical passive $A R$ is structurally represented as follows (with kare 'he' representing the case of yokisinakatta bakuhatu 'unexpected explosion' as well):

$$
\left[_{\mathrm{TP}} \text { sawagi }_{\mathrm{i}} \ldots\left[_{\mathrm{vP}} t_{\mathrm{j}} \ldots\left[_{\mathrm{VP}}\left[\text { pare }_{\mathrm{j}} \text {-niyotte }\right] \ldots\left[_{\mathrm{VP}} t_{\mathrm{i}}\left(t_{\mathrm{k}}\right)\right]\right]\left[_{v}<\text { osam }_{\mathrm{k}}, \mathrm{AR}>\right]\right]\right]
$$

The R osam 'suppress' internally pair-Merges to Type (1C) AR [-ACC], the consequence of which is that object NP sawagi 'disturbance' needs to raise to the Spec of TP to receive nominative case, while the agentive kare 'he' (or, the triggering causer yokisinakatta bakuhatu 'unexpected explosion') is demoted to a non-argument position followed by postposition ni(yotte).

True to the "in-between voice" characteristic of the TrAlt system, those R-AR's that belong to the (10b) and (10c) variations essentially follow the pattern of (10a) but display varying degrees of idiosyncratic variations. Thus, consider (13b) and (14b) with R's like atatam 'warm' and butuk 'hit', with which only the triggering causer subject is allowed in the context of R-AR.

a. $\quad$ Sumibi, Sue\}-ga soup-o atatam-E-ta.

\{charcoal.fire, Sue $\}$-NOM soup-ACC warm-E-PAST

'\{Charcoal.fire, Sue $\}$ warmed the soup.'

b. Soup-ga sumibi, *Sue $\}$-niyotte atatam- $A T$-ta. soup-NOM \{charcoal.fire, *Sue\}-by warm-AR-PAST

'The soup was warmed by $\{$ charcoal.fire, *Sue\}.'

( $A R$ here is a lexical passive, cannot be forced to behave as an intransitivizer.)

c. $*$ Sumibi, Sue $\}$-ga suupu-ni atatam-AT-ta. ${ }^{14}$

\{charcoal.fire, Sue\}-NOM soup-ACC warm-AR-PAST

(Intended: ' $\{$ Charcoal.fire, Sue $\}$ warmed by the soup.')

( $A R$ here is intended to be an intransitivizer.)

a. \{Toppuu, Sue\}-ga kuruma-o ki-ni butuk-E-ta.

\{gust.of.wind, Sue\}-NOM car-ACC tree-to strike-E-PAST

' $\{$ A.sudden.gust.of.wind, Sue $\}$ crashed the car into a tree'

b. Kuruma-ga \{toppuu, *Sue\}-niyotte ki-ni butuk-AT-ta. car-NOM \{gust.of.wind, *Sue\}-by tree-to strike-AR-PAST

'A car struck a tree by \{a.sudden.gust.of.wind, *Sue\}.'

c. *\{Toppuu, Sue $\}$-ga kuruma-ni ki-ni butuk-AT-ta. \{gust.of.wind, Sue\}-NOM car-ACC tree-to strike-AR-PAST

(Intended: ' $\{$ A.sudden.gust.of.wind, Sue $\}$ crashed the car into a tree')

( $A R$ here is a lexical passive.)

The variant (10c) allows the agent in the R-AR construction to take a postpositional $n i$ 'by', but not niyotte 'by':

14 An interesting fact about (13c) with Sue is that its acceptability increases if Sue is considered to be significantly affected by the soup. This issue, following Matsumoto's (2000c) lead, will be discussed in Section 3.3. In the same context, Sue becomes still more acceptable if suupu-niyotte 'by (means of) soup', instead of suupu-ni 'by soup', is used, emphasing the instrumental nature of 'soup.' With the R's of this group, therefore, these lexico-semantic peculiarities need somehow be registered in their lexical entries. 
a. Ten'in-ga manbiki-o mituk-E-ta clerk-NOM shop.lifting-ACC notice-E-PAST 'A clerk spotted shoplifting.'

b. Manbiki-ga ten'in-ni(??yotte) mituk-AT-ta.

shop.lifting-NOM clerk-by find-AR-PAST

'Shoplifting was spotted by a clerk.'

Besides those pairs listed in (10), there are Type (1C) (AR/E) R's like azuk 'entrust to', sazuk 'give', and iituk 'give order', which do not exactly follow the pattern of classification formulated in (9) and (10). They are all ditransitive R's involving the "Source, Goal, Theme" roles. In (16a), the Source Ken may double as the Agent, and Theme kamera 'camera' transports from the Source/Agent to the Goal Sue in some capacity.

a. Ken-ga Sue-ni kamera-o azuk-E-ta.

K-NOM S-DAT camera-ACC entrust-E-PAST

'Ken entrusted a camera to Sue.'

b. Sue-ga Ken-\{ni, kara\} kamera-o azuk-AT-ta.

S-NOM K-\{by, from $\}$ camera-ACC entrust-AR-PAST

'Sue was entrusted a camera by Ken.'

(Note that the status of $A R$ here is ambiguous: it is a lexical passive according to diagnostic test (9a), but "intransitivizer-like" according to (9b) in that Ken-

$\{n i, k a r a\}$ no longer has indirect object status.)

c. *Kamera-ga Ken-ni Sue-ni azuk-AT-ta. camera-NOM K-by S-to entrust-AR-PAST

(Intended: 'The camera was entrusted to Sue by Ken.')

d. Kamera-ga Ken-niyotte Sue-ni azuk-E-rare-ta.

camera-NOM K-by S-to entrust-E-PASSIVE-PAST

'The camera was entrusted to Sue by Ken.'

The attachment of lexical passive $A R$ to a ditransitive $\mathrm{R}$ like azuk 'entrust' thus strips away the indirect objecthood from the Goal argument, and promotes it to the subject position, converting the ditransitive status of this $\mathrm{R}$ to that of the transitive $\left(\left[[\mathrm{R}]_{\mathrm{dit}}-A R\right]_{\mathrm{tr}}\right)$. In this manner, the feature [-ACC] associated with $A R$ exposes the two faces of $A R$ manifesting in the same context: (i) with its "lexical passive" face, it demotes the "Source" subject Ken to the postpositional Ken-\{ni, kara\} 'from Ken'; and (ii) with its "intransitivizer-like" face, it reduces ditransitivity to transitivity by promoting the indirect object Sue-ni to be the subject. ${ }^{15}$

The specifics of those variations associated with the R's must be registered in their lexical entries. Here again, differences in the degree of acceptability associated with each of those cases accentuates the "in-between voice" characteristics associated with $A R$.

\subsection{The context for "being affected"}

Consider again example (13c), reproduced here as (17). To be noted here is that the sentence with the sentient subject Sue may turn out to be less odd if we assume that the mental, psychological, or physiological state of the subject referent Sue is significantly affected by the event expressed by the predicate (i.e., 'warmed by the soup').

$$
\begin{aligned}
& \{* \text { Sumibi, Sue }\} \text {-ga suupu-ni(yotte) atatam-AT-ta. } \\
& \text { \{charcoal.fire, Sue\}-NOM soup-by warm-AR-PAST } \\
& \text { ' }\{\text { *Charcoal fire, Sue }\} \text { was warmed by soup.' }
\end{aligned}
$$

(The status of $A R$ is ambiguous: it is a lexical passive with respect to the diagnostic test (9a) but an intransitivizer according to (9b).)

15 A question may also be raised, as pointed out by one of the reviewers of the earlier version of this paper: Why is it that the lexical passivization by $A R$ may promote the NP-ni (i.e., Sue-ni in (16a)) to the subject position as in (16b) but not NP-o (i.e., kamera-o in (16c)). I have no answer for this question at present. Suggestive about this issue is Perlmutter's (1978: 157) following comment: "Passive cannot be characterized as an advancement, but must be treated as a demotion of a1, with advancement of a2 to 1 as a language-particular option." 
In (18) too Sue is the significant "affectee" in the event of being hit by a car:

$$
\begin{array}{ll}
\text { Sue-ga kuruma-ni(*yotte) } & \text { butuk-AT-ta. } \\
\text { S-NOM car-to } & \text { hit-AR-PAST }
\end{array}
$$

'Sue was hit by a car."

( $A R$ is a lexical passive with respect to the diagnostic test (9a), but is an intransitivizer according to (9b).)

What is common with (17), (18b), and other similar constructions are the curious "affectee" status of the subject NP referent and the concomitant ambiguous status of $A R$ of being either a lexical passive or an intransitivizer.

This is reminiscent of the phenomenon pointed out by Matsumoto 2000c in relation to a transitive and ditransitive pair like osie-ru 'teach' and osowar- $u$ 'learn'. Thus, consider the following pair:

$$
\begin{aligned}
& \text { a. Sensei-ga seito-ni eigo-o osie-ta. } \\
& \text { teacher-NOM student-to English-ACC teach-PAST } \\
& \text { 'the teacher taught the students English.' } \\
& \text { b. Seito-ga sensei-ni eigo-o osowat-ta. } \\
& \text { student-NOM teacher-by English-ACC learn-PAST } \\
& \text { 'Students learned English from the teacher.' }
\end{aligned}
$$

Matsumoto (2000c: 82) notes that the felicity requirement for the transitive osowar-ru and ditransitive osie-ru type pairs is that the subject NP referent of the transitive construction (which corresponds to the referent of the NP-ni in the ditransitive) must be associated with a sense of being significantly affected by the event described by the predicate. Thus, in the case of (19), seito 'student' is the significant affectee in the event "English lesson."

\section{Productivity phenomena of $A R$}

Transitive suffix $A R$ engages in productivity phenomena in two markedly different manners: one associated with substandard status, and the other with no such stigma.

\subsection{Type (1E) $\{A R / \varnothing\} A R$ and its substandard productivity}

Recall that, of those of Jacobsen's (1992) eight pairs that belong to the Type (1E) pattern, we have identified two pairs wherein the $\mathrm{R}$ demands the lexical passive $A R$ (i.e., (3b) and (4b)) and two others with which the $\mathrm{R}$ calls for the intransitivizer $A R$ (i.e., (6b) and (7b)). This is the picture that fits Hasegawa's (2001: 2) characterization, namely, that Japanese TrAlt is a system wherein it is "not predictable" which suffix a particular R takes. This is the underlying assumption behind Jacobsen's (1992) "Appendix list” as well.

There exist, however, Type (1E) R-AR constructs not listed in Jacobsen's “Appendix." They are instances of what Kageyama (1996: 191-192) calls zoogo 'new word creation' notwithstanding their substandard status. He cites the following four cases from Miyaji (1985), in which examples from well-known literary works are painstakingly collected: e.g., [dak-AR $]_{\text {intr }} \leftarrow[\text { dak }]_{\text {tr }}$ 'hold on' (Miyaji 1985: 285-287, (3); Kageyama 1996: 192, (128e)); [musub-AR $]_{\text {intr }} \leftarrow[m u s u b]_{\text {tr }}$ 'tie' (Miyaji 1985: 295-296; Kageyama 1996: 192, (128d)); [os-AR $]_{\text {intr }} \leftarrow[o s]_{\text {tr }}$ 'put (a seal) on' (Miyaji 1985: 288, (3); Kageyama 1996: 192, (128c)); [turus-AR $]_{\text {intr }} \leftarrow[\text { turus }]_{\text {tr }}$ 'hang' (Miyaji 1985: 291-292; Kageyama 1996: 192, (128a)). A case of $\left[[d a k]_{\mathrm{tr}}-\{A R / \varnothing\}\right]_{\text {intr }}$ is exemplified in (20a) along with the perfectly natural direct passive version in (20b).

a. ?Ho, konnani ookiku.nat-ta. Dore, dak-AT-te mi-ro. Wow like.this big.become-PAST well embrace-AR-and try-IMP 'Wow, you've grown big. Well, let me hold you (lit. get yourself be held by me).' (from Tayama Katai's novel, Toki-wa Sugiyuku 'Time passes by')

b. Ho, konnani ookiku.nat-ta. Dore, dak-are-te mi-ro. Wow like.this big.become-PAST well embrace- PASSIVE-and try-IMP 'Wow, you've grown big. Well, let me hold you (lit. get yourself be held by me).' 
Miyaji's own list of these formations further includes the following: " $[m u s-A R]_{\text {intr }} \leftarrow[m u s]_{\text {tr }}$ 'steam cook" (Miyaji 1985: 293-294); "[nuk-AR $]_{\text {intr }} \leftarrow[n u k]_{\text {tr }}$ 'pull out"” (Miyaji 1985: 301305); "[sik-AR $]_{\text {intr }} \leftarrow[s i k]_{\text {tr }}$ "lay out" (Miyaji 1985: 283-287); "[tatam-AR $]_{\text {intr }} \leftarrow[\text { tatam }]_{\text {tr }}$ "fold'” (Miyaji 1985: 297-298), “[tutum-AR] $]_{\text {intr }} \leftarrow\left[_{\text {tutum }}\right]_{\text {tr }}$ 'enclose”" (Miyaji 1985: 299-300).

For Kageyama (1996: 191), these Type (1E) R-AR constructs exemplify "new word creation." With Nishio (1954), these are instances of new word creation made in "analogy" to the Type (1E) $\{A R / \varnothing\}$ pattern. How about their substandard status? The answer is clear enough. As Kageyama (1996: 191-192) points out, the reason for their substandard status has to do with the fact that the transitive R's that are involved here are those that are normally considered to "lack the intransitive counterparts." The lexical passive $A R$ is attached illegally to those transitive R's. In these cases, the lexical passive $A R$ masquerades as a direct passive. (Kageyama also notes that these R's constitute a natural lexico-semantic class, being of "the kind that expresses a state or a change of location.")

Indeed, these R's under discussion have all the signatures of the transitive R's that "lack the intransitive counterparts" according to various empirical tests advanced in Hayatsu (1989). She observes, on the basis of such phenomena as agentive nominalization, iteration phenomenon, co-occurring adverbs, and compound verb formation, that there is a notable lexico-semantic contrast between the transitive R's that participate in TrAlt and those that do not, clustering around the aspectual sense of "result." The R's that do not participate in TrAlt tend to be those that express a sense of process; they are aspectually [-state, +durative, -telic] with the telic feature fixed as [-telic]. In contrast, the R's that do participate in TrAlt can relate to the resulting points of eventuality; it is normally the kind that is aspectually characterized as [-state, +durative, +telic]. Thus, the capacity of an $\mathrm{R}$ to express an ongoing process can be a test to tease apart those two types of R's (Hayatsu 1989: 240-243). And, the R's in the R-AR examples exhibiting substandard status (e.g., dak 'hug' in (20a)/(21a), nom 'drink' in (21b)) are exactly those that have the capacity of expressing an ongoing process, as the following examples show:

a. Ano ko-wa sakki-kara hahaoya no syasin-o mune-ni

that kid-TOP a.while.ago-from mother 's photo-ACC chest-to

daki-tuzuke.te i-ru.

hold-continue.and be-PRES

'That kid has been holding his mother's photo to his chest for some time now.'

b. Kare-wa hitoban.zyuu sake-o nomi-tuzuke-ta.

he-TOP all.night.long rice.wine-ACC drink-continue-PAST

'He just kept drinking sake all night long.'

These examples demonstrate that the R's that appear in substandard R-AR's like dak-AR 'be held' are of the type that do not participate in TrAlt. Hence, dak-AR is illegal and marked as substandard. In popular usage, such substandard R-AR constructs are quite unstable. My sense is that, while an example like dak- $A R$ 'be embraced' in (20) is fairly understandable, an example like mus-AR 'be steam-cooked' of $\left[[m u s]_{\text {tr }}-\{A R / \varnothing\}\right]$ in the following example taken from Yokomitsu Riichi's novel Hai 'Flies' (1923) (Miyaji 1985: 293) goes beyond the permissible line today:

$$
\begin{aligned}
& \text { ?* Manzyuu-wa mada mus-AR-an no kai? } \\
& \text { dumpling-TOP yet steam-PASs-not is.it Q } \\
& \text { (Intended: 'Are the dumplings not steam-cooked yet?') }
\end{aligned}
$$

As Miyaji notes most of these substandard forms disappear in time.

What is important to note, at the same time, is that this substandard productivity phenomenon is highly symptomatic of the passive-like function of a lexical passive $A R$, contributing to the TrAlt's "in-between" voice status. Native speakers of Japanese are quite aware, and indeed quite ready to take advantage, of the distinct passive-like force associated with the lexical passive $A R$, even risking the consequence of its substandard status. That is to say, the $v$ suffix $A R$ here is not subjugated entirely to its host R's idiosyncratic lexico-semantic property. On one hand we do need to acknowledge that each $\mathrm{R}$ participating in TrAlt must be registered in the dictionary for its co-occurrence potential with $A R$. But, on the other, the substandard behavior of $A R$ 's noted 
in this subsection shows that the same $A R$ 's can act like syntactically active passives. $A R$ here is behaving badly, but potentially not so prohibitively. And, this, of course, is what we might expect from the Japanese TrAlt, which is an "in-between" voice system.

\subsection{Productivity phenomena involving the Type (1C) $\{A R / E\}$ pattern}

Unlike the substandard productivity of Type (1E) $\{A R / \varnothing\} A R$, the productivity involving Type (1C) $\{A R / E\} A R$ is quite robust and stable.

Noteworthy for our purpose are the fascinating diachronic findings by Nishio (1954). He lists three historically classified periods as in (23a), (23b), and (23c), in terms of which the productivity pattern involving the derivational directionality of $[\mathrm{R}-A R]_{\text {intr }} \leftarrow[\mathrm{A}-E]_{\text {tr }}$ can be traced with remarkable clarity. Taking the data in (23a) to be the constant, Nishio shows that the newly created Type (1C) $[\mathrm{R}-A R]_{\text {intr }}$ forms increased as time went on, as shown in (23b) and (23c).

a. Both members of the Type (1C) $\left\{[\mathrm{R}-A R]_{\text {intr }} /[\mathrm{R}-E]_{\mathrm{tr}}\right\}$ doublet pairs are found in literary texts throughout the period from the Nara period (710-794 AD) to the present time: e.g., $a g-\{A R / E\}$ ' $\{$ go up/lift $\}$ ', $k a k-\{A R / E\}$

' connect $_{\text {intr }}$ /get.connected $\left._{\mathrm{tr}}\right\}$ ', kaw- $\{A R / E\}$ ' $\left\{\right.$ change $_{\text {intr }}$ /change $\left._{\mathrm{tr}}\right\}$ ', kasan- $\{A R / E\}$ '\{ pile.up $_{\text {intr }} /$ pile.up $\left._{\text {tr }}\right\}$ ', mag- $\{A R / E\}$ ' $\left\{\right.$ bend $_{\text {intr }}$ /bend $\left._{\text {tr }}\right\}$ ', tom- $\{A R / E\}$ ' $\left\{\right.$ stop $_{\text {intr }} /$ stop $\left._{\text {tr }}\right\}$ ' (Nishio 1954: 106).

b. There is a batch of the $[\mathrm{R}-A R]_{\text {intr }}$ constructs that make their appearance only in the literary texts written after $1,600 \mathrm{AD}$, while their corresponding $[\mathrm{R}-E]_{\text {tr }}$ constructs are found in the literary texts throughout the period from the Nara period (710$794 \mathrm{AD}$ ) to the present time: e.g., sazuk- $\{A R / E\}$ ' $\{$ be.given/give $\}$ ', $\operatorname{tasuk}-\{A R / E\}$

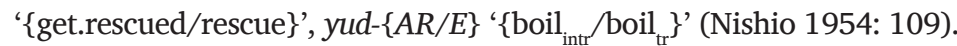

c. There is still another body of the $[\mathrm{R}-A R]_{\text {intr }}$ constructs which appear only in the literary texts written (and published) after the time of the Meiji reformation (the first year of the Meiji period is 1868), while their corresponding $[\mathrm{R}-E]_{\mathrm{tr}}$ constructs were found in the literary texts from the Nara period (710-794 AD) on: e.g., $u k-$ $\{A R / E\}$ ' $\{$ pass.a.test/take.a.test $\}$ ', tutom- $\{A R / E\}$ ' $\left\{\right.$ serve $_{\text {intr }} /$ serve $\left._{\text {tr }}\right\}$ ', iituk- $\{A R / E\}$ '\{get.ordered'/'order $\left.{ }_{\text {tr }}\right\}$ ', $u k$ ' ' pass $_{\text {intr }} /$ take $\left._{\text {tr }}\right\}$ '. (Nishio 1954: 105-106).

What this picture shows is that prior to the emergence of the new $\left[[R]_{\mathrm{tr}}-A R\right]_{\mathrm{intr}}$ forms in each of the stages (23b) and (23c), the corresponding $\left[[R]_{\mathrm{tr}}-E\right]_{\mathrm{tr}}$ forms had already existed. Nishio claims on the basis of this that the formation of the new $[\mathrm{R}-A R]_{\text {intr }}$ constructs must have taken place in analogy to the existing Type (1C) $\left\{\left[[R]_{\text {tr }}-A R\right]_{\text {intr }} /\left[[R]_{\text {tr }}-E\right]_{\mathrm{tr}}\right\}$ pattern already available in the stage (23a). This productivity process was apparently quite robust, which would attest to the fact that the type (1C) $\{A R / E\}$ pattern is by far the largest group in (1). It would also lead us to speculate that there may well be far more actual cases of the Type (1C) $\mathrm{R}-\{A R / E\}$ pairs beyond those listed by Jacobsen's (1992) “Appendix.” In fact, Miyaji's list of such unlisted pairs includes kagam- $\{A R / E\}$ 'squat' (Miyaji 1985: 227-233), mak-\{AR/E\} 'reduce in price' (Miyaji 1985: 88-89), and sukum $\{A R / E\}$ 'cower' (Miyaji 1985: 204-208).

Nishio thus identifies, for the first time in literature, the fact that the derivational directionality " $\left[[\mathrm{R}]_{\mathrm{tr}}-A R\right]_{\text {intr }} \leftarrow\left[[\mathrm{R}]_{\mathrm{tr}}-E\right]_{\mathrm{tr}}$ " is a factor in creating the new R- $v$ formation of the Type (1C) $\{A R / E\}$ pattern, although the other way around (i.e., $\left[[R]_{\mathrm{tr}}-A R\right]_{\text {intr }}{ }^{\circledR}\left[[R]_{\mathrm{tr}}-E\right]_{\mathrm{tr}}$ ) is possible as we saw in the case of tatiag-E 'start up' (see fn.3). He fails to provide, however, a satisfactory account as to why that should be the case (see, especially, Nishio 1954: 113). I suspect that the reason for this is his preoccupation with "analogy" as the basic driving force for new word formation. We will return to the question of the derivational directionality favoring " $\left[[R]_{\mathrm{tr}}-A R\right]_{\text {intr }} \leftarrow\left[[R]_{\mathrm{tr}}-E\right]_{\mathrm{tr}}$ " in Section 7.

\section{Lexical causative AS}

In the view that has been widely accepted since Kuno (1973) and Shibatani (1973), the distinction between the "lexical causative" with $A S$ and the syntactically active causativizaton by periphrastic $(s)$ ase is made in terms of the monoclausal $v s$. biclausal characterizations gauged 
by such means as reflexive zibun 'self' interpretation involving its subject-antecedent condition and the subject-oriented adverbial interpretation. The lexical causative R-AS construction (24a) is monoclausal with just one subject NP (i.e., Hanako), and the periphrastic (s)ase causative (24b) is biclausal with two distinct subject NPs (i.e., Hanako as well as Taro). In these examples, $A S$ is glossed simply as "AS," while the periphrastic causative (s)ase is glossed as 'cause.'

a. Hanako-wa Taro $_{\mathrm{j}}$-o zibun ${ }_{\mathrm{i} /{ }^{*} \mathrm{j}}$ no heya-de nak-ASi-ta.

H-TOP T-ACC self 's room-in weep-AS-PAST

'Hanako ${ }_{i}$ made Taro cry in her ${ }_{i}$ room.'

b. Hanako ${ }_{i}$-wa Taro $_{j}$-o zibun ${ }_{i / j}$ no heya-de nak-ase-ta.

H- TOP T-ACC self 's room-in weep-cause-PAST

'Hanako ${ }_{\mathrm{i}}$ made Taro $_{\mathrm{j}}$ cry in his ${ }_{\mathrm{i}}$ /her $_{\mathrm{j}}$ (own) room.'

\subsection{Paradigmatic structure}

If, however, the difference between lexical causative $A S$ and (s)ase causativization is primarily defined in terms of the monoclausal vs. biclausal test, complications arise. Matsumoto (2000a: 146-51) demonstrates, using examples such (25), that periphrastic (s)ase causativization of certain transitive verbs (e.g., tabe-ru 'eat', sir-u 'know', hak-u 'put on, wear') that do not participate in TrAlt may function as "lexical" (s)ase causatives, if the set of conditions listed in (26) are met.

$$
\begin{aligned}
& \text { Anpanman }_{\mathrm{i}} \text {-ga } \text { akatyan }_{\mathrm{j}} \text {-ni } \text { karezisin }_{\mathrm{i},{ }^{\mathrm{j}} \mathrm{j}} \text {-o } \text { tabe-sase-ta. }^{16} \\
& \text { Anpanman-NOM baby-DAT he.himself-ACC eat-cause-PAST } \\
& \text { 'Anpanman gave his own body to feed the baby.' }
\end{aligned}
$$

The R-(s)ase causative may function as "lexical causative" (R-AS) if the R represents a process whereby
(a) the subject referent is affected or at least undergoes some change;
(b) the event described is mostly due to "self-directed" actions; and
(c) the event is the kind that is conducted with the agent herself as the recipient or beneficiary of a moved entity or influence.

If satisfied, Matsumoto notes, they exhibit syntactically "monoclausal" characteristics as judged by such tests as subject honorification, passivization of the object NP of the base R, pronominal binding, Control, and subject oriented adverbial interpretation. The fact that reflexive karezisin 'herself, himself' may refer to the subject Anpanman in (25) indicates that the sentence is monoclausal, because, as generally accepted, karezisin "must be bound within its clause" (Matsumoto 2000a: 148). So, we now have a question: what is the status of (s)ase in (25)? Is it still a syntactically active periphrastic causative?

A significant attempt to respond to such a question is Miyagawa's (1980; 1984; 1998) "Paradigmatic Structure" (PDS) thesis. So, although not directly bearing upon the main issues of this paper, let me provide a brief comment. The PDS, specifying three slots (Intransitive, Transitive, and Ditransitive), purports to be a system in terms of which a verb, either simple or complex, can be "placed into an appropriate slot" (Miyagawa 1984: 186); as such, it constitutes "an organization within the lexicon that filters as to which verbs may enter the permanent lexicon" (Miyagawa 1998: 71). In (24), transitive tabe 'eat' being an R that does not participate in TrAlt, tabe-sase 'eat-cause' fits into the PDS's ditransitive slot. This system provides a principled way to explain, for instance, why the intransitive R niow 'smell' lacking the transitive partner may adopt the causative form niow-ase 'smell-cause' to constitute an idiom that means "hint" (Miyagawa 1998: 71, M’s (11)).

16 See Matsumoto (2000a: 149, (14c)). He provides no test examples involving logophoric reflexive zibun 'self'. But, the following seems fine to me, proving the same point.

(i) Yasya $\mathrm{i}_{\mathrm{i}}$-wa kodomo $_{\mathrm{j}}$-ni zibun $_{\mathrm{i},{ }^{*} \mathrm{j}}$-o tabe-sase-ta.

Yasya-TOP child-DAT self-ACC eat-cause-PAST

'Yasya gave her own body to feed her children.' (Yasya is a legendary figure who fed her

children with her own flesh when their lives were threatened with starvation.) 
Miyagawa (1998) admits, however, that his PDS has difficulty in handling triplets, which involve two distinct lexical forms competing for just one PDS slot (e.g., $\left[\mathrm{mor}_{\mathrm{intr}}\right.$ 'leak $_{\text {intr }}$ ' and $[m o r-E]_{\text {intr }}{ }^{\text {'leak }}{ }_{\text {intr }}$; or $[t o k]_{\mathrm{tr}}$ 'dissolve ${ }_{\mathrm{tr}}$ ' and $[t o k-A S]_{\mathrm{tr}}$ 'dissolve ${ }_{\mathrm{tr}}$ ').

\subsection{Two types of causation}

Kageyama (1996) makes an important contribution to our understanding of the nature of causation expressed by AS. He takes advantage of the fact that some R's expressing animate motion of "self-induced change" may occur either with the $A S$ oriented (1F) R- $\varnothing / A S\}$ pattern or with "transitivizing" $E$ forming Type (1A) R- $\varnothing / E\}$. Analyzing the semantic distinction between $A S$ and $E$ in this minimal pair context in terms of his "Lexical Semantic Relation" (LSR) framework, he concludes that AS may accommodate a "triggering causer," while $E$ calls for a "volitive NP" as its external argument EA (Kageyama 1996: 69-77; 190198). His claim is based on examples like the following (Kageyama 1996: 197, K's (137b) and (138b)):
a. \{Kodomo, *Densya.no.sindoo\}-ga isi-o narab-E-ta.
\{child, train's.vibration\}-NOM stone-ACC line.up-E-PAST
'\{Children, *The train's vibration\} made the stones line up.'
b. \{Kodomo, Densya.no.sindoo\}-ga isi-o ugok-ASi-ta.
\{Child, train's.vibration\}-NOM stone-ACC move-AS-PAST
'\{Children, The train's vibration\} made the stones move.'

In (27a) with $E$, the sentient EA kodomo 'child' qualifies to be a volitive NP, while the nonsentient EA densya no sindoo 'train's vibration' does not, thus rendering the latter infelicitous. In example (27b), $A S$, which simply requires its EA to be a triggering causer, fits in with either animate kodomo 'child' or inanimate densya no sindoo 'train's vibration'; hence, both are felicitous in (27b).

Suga (1980: 37, (58) and (60)) notes a similar contrast:
a. Kare-wa soko-ni ana-o ak-\{E, *ASi $\}$-ta.
He-TOP there-DAT hole-ACC open- $\{E, * A S\}$-PAST
'He opened a hole there.'
b. Kare no setumei-ga doori-o ak- $\{* E, A S i\}$-ta.
he 's explanation-NOM logic-ACC open- $\left\{{ }^{*} E, A S\right\}$-PAST
'His explanation made the logic clear.'

Sentence (28a) calls for a volitive EA, providing a context favorable to $E$ but not to AS. In (28b) with inanimate EA, the situation is the reverse: only $A S$ that relates to triggering causation is felicitous.

Matsumoto (2000b) presents a critique of Kageyama's claim, stating that the distinction between - $e$ and -as is "only an accidental product of his examples," and that "the distinction comes from the semantics of the base verb rather than from the affix chosen" (Matsumoto 2000b: 178). In his view, $-e$ and -as "both trigger causativization in a similarly indeterminate way, allowing different possibilities for the nature of their subject"; "this kind of distinction" is "a part of the regular semantics of each semantic type of verb" (Matsumoto 2000b: 181). I concur with the view that the distinction comes from the semantics of the base R. In this, however, I adopt the line of analysis suggested by Arad (1998: 124). She proposes: "we should distinguish not between agents and causers as such but between predicates selecting for an agent and predicates which allow a causer." For, "agents and causers are generated in the same syntactic position, Spec $v \mathrm{P}$." Selection of $v^{*}$ suffix $E^{*}$ by V is the "something more" which distinguishes agents from causers, allowing a volitive agent in its Spec $v \mathrm{P}^{*}$. If a given $\mathrm{R}$ like $a k$ 'open' selects either $A S$ or $E$, the contrastive semantic characteristics associated with $A S$ or $E$ may then manifest as exemplified in (28a) and (28b). Following Kageyama, I thus maintain that $A S$ may call for a "triggering causer." As for $E$, a detailed analysis of it follows directly. 


\section{Multi-facet manifestation of TrAlt Suffix $\mathbf{E}$}

As Narrog (2016: 257) points out, "a common assumption" about $E$ from a diachronic point of view is the following: ${ }^{17}$

the vowel $-e$ in the verb base goes back to a morpheme *-Ci (e.g., Unger 2000: 664, $667)$ that Robbeets $(2007,2010)$ labels as "causative-passive" and identifies as *- $k) i$. Traditionally it has been assumed that this is related to causative-passives in Korean and other Transeurasian languages.

It is this "causative-passive" suffix E, viewed synchronically, that is our topic in this section.

Jacobsen (1992: 57) notes that two of the main classes of verb pairs "exhibit the same suffixes, but marking precisely the opposite sides of the intransitive $v s$. transitive opposition." These are the groups that are identified in (1) as Types (1A) R- $\varnothing \varnothing / E\}$ with "transitivizing" $E$ and (1B) $\mathrm{R}-\{E / \varnothing\}$ with "intransitivizing" $E$. It is largely the difficulty of treating these $E$ 's either as one morpheme or two that has forced researchers like Okutsu (1697) to conclude that $E$ is simply part of R. Sakuma (1936: 137) has noted: "it is clear that -ar is involved with intransitivization and -as with transitivization," but "- $e$ is involved with both, depending on the situation; herein may lie an important clue to unlock the system of verbal constructions in Japanese." It is with this backdrop that I will attempt to present a unified analysis that these E's are in fact all instances of one and the same $v$ suffix $E$.

Suffix E's chart (1) appear in the following four different patterns:

\begin{tabular}{|c|c|c|c|c|c|}
\hline ype & Suffix $\mathrm{Pa}$ & Intransitive, e.g. & & & \\
\hline & $\{\varnothing / E\}$ & sizum 'sink $_{\text {intr }}$ ' & sizum-E 'sink & 34 & $(38)$ \\
\hline & $\{E / \varnothing\}$ & or- $E$ 'break ${ }_{\text {intr }}$ ' & or 'break ${ }_{\text {tr }}$ ' & 30 & $(38)$ \\
\hline & $\{A R / E\}$ & mag- $A R$ 'bend ${ }_{\text {intr }}$ ' & mag- $E$ 'bend ${ }_{\mathrm{tr}}$ & 70 & $(58)$ \\
\hline $\mathrm{D}=2$ & $\{E / A S\}$ & kog-E 'burn ${ }_{\text {intr }}$ ' & kog-AS 'burn ${ }_{\mathrm{tr}}$ ' & 45 & (42) \\
\hline
\end{tabular}

Of these four, $E$ in Type (1A) $\{\varnothing / E\}$ appears to contribute to the transitive status of R-E ([R-E $\left.]_{t r}\right)$, and that in Type (1B) $\{E / \varnothing\}$ to the intransitive $\left([R-E]_{\text {intr }}\right)$. A natural but heretofore seldom asked question is the following: What about the E's that appear in Types (1C) $\{A R / E\}$ and (1D) $\{E / A S\}$ ? In order to clarify this picture, let me first appeal to Marantz's (1984: 128) "No Vacuous Affixation principle" stated in (30a), which can be translated for our purpose as in (30b).

$$
\begin{aligned}
& \text { a. For a certain class of features } \mathrm{F} \text {, an }\left[+ \text { alpha } \mathrm{F}_{\mathrm{i}}\right] \text { affix may attach only to a } \\
& {\left[\text {-alpha } \mathrm{F}_{\mathrm{i}}\right] \text { root. }} \\
& \text { b. Root Class Identification Algorithm: } \\
& \text { (i) If } \mathrm{R}+A R \text { is presented, then R-category }=\mathrm{R}_{\mathrm{tr}} \text {; } \\
& \text { (ii) If } \mathrm{R}+A S \text { is presented, then R-category }=\mathrm{R}_{\text {intr }} \text {. }
\end{aligned}
$$

Notice that, viewed thus, Marantz's No Vacuous Affixation principle would dictate that the E's in Type (1C) $\{A R / E\}$ and Type (1D) $\{E / A S\}$ contribute absolutely nothing to the transitivity status of their R's. Given these properties of $E$ 's, the root class identification algorithm for suffix $E$ can be stated as follows:

17 Whitman (2008) and Frellesvig \& Whitman (2016) propose an alternative view that the intransitivizing $E$ originates from "verb $e$ - 'get, obtain, be able to'." The combination of the basic root of a verb with the verb $e$ "results in the subregularities that survive to this day: transitive accomplishment verbs from the combination of 'get' with intransitive achievement, and a smaller number of anticausative intransitives from the combination of 'get' with transitives" (Frellessvig and Whitman 2016: 289). Whitman (2008: 165) is certainly correct when he says that "whatever morpheme was involved in the derivational relationship linking quadrigrade and bigrade stems, it was not a simple "transitivity flipper"' (such as suggested, in my view, in an extensive diachronic study by Mabuchi 1999: 300-301 or in a synchronic account of $E$ in Kitagawa \& Fujii 1999). To be noted, however, is that one possible meaning of their "verb $e$-" is 'be able to'. And this is a problem. Synchronically, potential auxiliary (rar) $e$ 'be able to' is distinct from $v$ suffix $E$ in one critical respect. It can attach to a transitive $\mathrm{R}$ that does not participate in TrAlt (e.g., nom 'drink', tabe 'eat'):

(i) Satoo-o ire-ru to dare.de.mo oisiku nom-e-ru. sugar-ACC put.in-PRES if anybody deliciously drink-be.able.to-PRES. 'If you put in sugar, anyone can drink it smoothly.'

(ii) Sio-o kake-ru to oisiku tabe-rare-ru. salt-ACC sprinkle-PRES deliciously eat-be.able.to-PRES 'If you sprinkle salt over it, you can enjoy eating it.' 
That is, if a given R-E is $[\mathrm{R}-E]_{\text {tr }}$, then, its R-category is intransitive if it participates in Type (1A)

$\{\varnothing / E\}$, or transitive in case it participates in Type (1C) $\mathrm{R}-\{A R / E\}$. Likewise, if a given R-E is

$[\mathrm{R}-E]_{\text {intr }}$, the R-category is transitive in the case of Type (1B) $\mathrm{R}-\{E / \varnothing\}$ or intransitive in the case of Type (1D) $\mathrm{R}-\{E / A S\}$. What, then, is the essential semantic property associated with the suffix $E$ encompassing Types (1A), (1B), (1C), and (1D)?

\subsection{Lexico-semantic properties associated with E's}

First of all, what about the lexico-semantic properties of the E's that appear in Type (1C) $\mathrm{R}-\{A R / E\}$ or Type (1D) R- $\{E / A S\}$ ? Informative for this inquiry is Hayatsu's (1989) observation referred to in Section 4.1, concerning the lexico-semantic contrast between the transitive R's that participate in TrAlt and those that do not. To reiterate: the R's that do not participate in TrAlt tend to be those that express a sense of process; they are aspectually [-state, + durative, -telic] with the telic feature fixed as [-telic]. In contrast, the R's that do participate in TrAlt can relate to the resulting points of eventuality; it is normally the kind that is aspectually characterized as [-state, + durative, + telic]. Thus, the E's that appear in Type (1C) R- $\{A R / E\}$ or Type (1D) R- $\{E / A S\}$ should, at the least, be those that can relate to a resultant state.

\subsection{Feature [+Resultant]}

Suga (1980) provides important empirical evidence for the view that the critical lexico-semantic property of $E$ can be represented in terms of the feature [+ Resultant]. He focuses on the triplet formation involving the $[\mathrm{R}-E]_{\mathrm{intr}},[\mathrm{R}-\varnothing]_{\text {intr }}$, and $[\mathrm{R}-A S]_{\mathrm{tr}}$ constructs which share the identical intransitive $\mathrm{R}$ (the $\mathrm{R}$ is intransitive here, given $\left[[\mathrm{R}]_{\mathrm{int}}-A S\right]$ ). This context provides a minimal pair of the two intransitive forms, $\left[[R]_{\text {intr }}-\varnothing\right]_{\text {intr }}$ and $\left[[R]_{\text {intr }}-E\right]_{\text {intr }}$, displaying a delicate division of labor: the unmarked form $[\mathrm{R}-\varnothing]_{\text {intr }}$ refers straightforwardly to the event that the R expresses, while the marked form $[R-E]_{\text {intr }}$ highlights the resultant state.

Thus, consider the case of $\left[[m o r]_{\text {intr }}-\varnothing\right]_{\text {intr }}$ and $\left[[m o r]_{\text {intr }}-E\right]_{\text {intr }}$ (mor 'leak, escape'):

a. Suidookan-kara mizu-ga mor-u.

water.pipe-from water-NOM leak-PRES

'Water leaks from the water pipe.'

b. Suidookan-kara mizu-ga mor-E-u. water.pipe-from water-NOM leak-E-PRES

'Water leaks from the water pipe.'

(Suga 1980: 35, (32A,B))

a. *Kimitu-ga teki-ni mor-u. secret-NOM enemy-DAT leak-PRES

(Intended: 'The secret leaks to the enemy.')

b. Kimitu-ga teki-ni mor-E-ru. secret-NOM enemy-DAT leak-E-PRES

'The secret leaks out to the enemy.'

Suga (1980: 35, (34A,B))

a. *Meibo-kara watasi no namae-ga mor-u. register-from I 's name-NOM escape-PRES (Intended: 'My name is not listed in the register.')

b. Meibo-kara watasi no namae-ga mor-E-ru. register-from I 's name-NOM escape- $E$-PRES 'My name is not listed in the register.' Suga (1980: 35, (35A,B))

According to Suga (1980: 35), "X-ga mor" means 'X moves out (from where it was located earlier)'. If this "movement" can be visibly traced, as in (32) with water flow, both (32a) the event of water leaking (mor) and (32b) the resultant state of water having leaked (mor-E) 
can both be felicitous; the difference between them is negligible and contributes to no grammaticality discrepancy, as seen in the English translations of (32a,b). If, on the other hand, the movement is the kind that can only be ascertained from its resultant state, as in the case of "secret" in (33) or a person's "name" in (34), then, the difference between the $\left[[R]_{\text {intr }}-\varnothing\right]_{\text {intr }}$ in (a) and the $\left[[R]_{\text {intr }}-E\right]_{\text {intr }}$ in (b) does contribute to the grammaticality discrepancy. In a situation depicted by (33), for instance, it is the resultant state that is critical precisely because the point to be communicated by (33) has to do with where the top-secret leak ends up, whether the enemy gets hold of it or not. In this context, the use of mor- $\varnothing$ in (33a) would display a woeful lack of understanding concerning the grammaticalized division of labor that mor- $\varnothing$ vs. mor-E instantiates.

To cite another example from Suga (1980), namely, the case of ter 'shine, flash'.

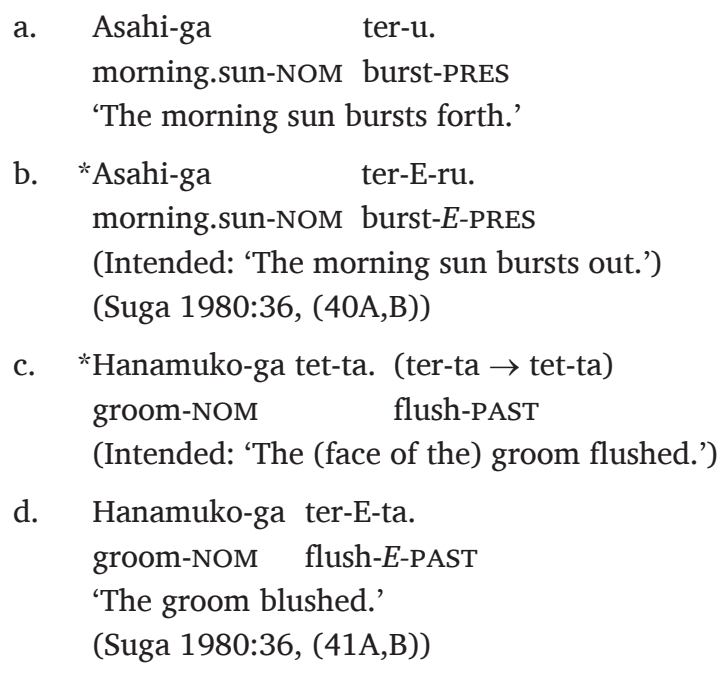

In terms of the grammaticality discrepancy, the relationship of (35a) to (35b) is the exact opposite of the relationship of (35c) to (35d). With the morning sun in (35a) and (35b), it is natural to describe it as bursting forth gloriously, but it is odd to describe it in terms of the resultant state of bursting out (whatever that means). On the other hand, it is peculiar to describe a groom flushing as in (35c), but it is perfectly understandable if he blushes as the result of an embarrassment as described in (35d). ${ }^{18}$

18 Still another example, this time having to do with suk 'become spacious.become' follows:

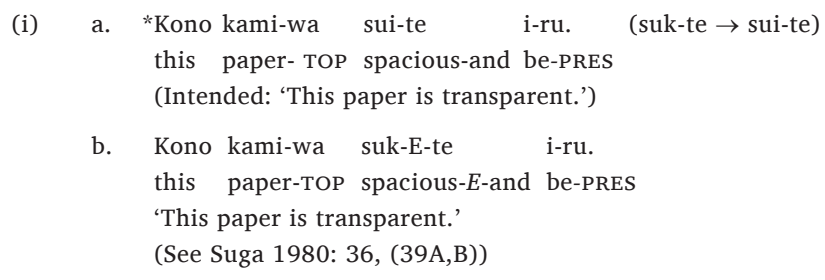

Suga (1980: 36) accounts for the grammaticality discrepancy as follows: "x's suk" means that "the distance between the x's gets broadened" interpreting x's to be the 'fibers', whereas "x's suk- $E$ " refers to the resultant state of the distance between the fibers becoming broadened. According to example (ia), the movement of the fibers broadening is still taking place, which is odd in the context, rendering it infelicitous. Example (ib) expresses, on the other hand, the resultant state of the fibers being broadened and, hence, transparent.

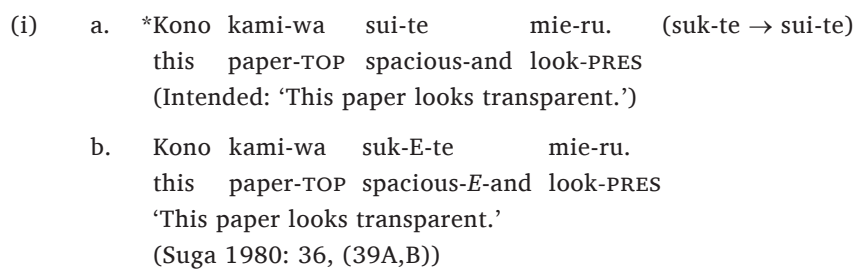

Suga (1980: 36) accounts for the grammaticality discrepancy involved here, as follows: "x's suk" means that "the distance between the X's gets broadened" interpreting x's to be the 'fibers', whereas "X's $s u k-E$ " refers to the resultant state of the distance between the X's becoming broadened (the situation fitting (iib), interpreting x's to be the 'fibers'). 
I will thus posit as a plausible working hypothesis that $v$ suffix $E$ is uniquely characterized by the feature [+ Resultant]. In the succeeding subsections we examine how this feature [+ Resultant] affects the interpretation of the R-E's depending on the given R's verb types: i.e., unaccusative, unergative, or accomplishment.

\subsection{E attachment to unaccusative R's}

Recall that in Section 5.1 we concurred with Kageyama (1996) that the $[R-E]_{\text {tr }}$ in Type (1A) $\{\varnothing / E\}$ calls for a volitive NP in the subject position. In the sense of Chomsky (2013: 43, fn. 29), the $E$ of this type is $v^{*}$. I therefore maintain that in Type (1A), wherewith $E$ 's involve transitivity directly, the resultant state is one that is effected by an outside force:

The feature [ + Resultant] associated with $E$ may imply an outside force effecting the resultant state.

According to Jacobsen (1992: 77), the type of R's participating in Type (1A) $\{\mathrm{R}-\varnothing / E\}$ as "transitivizing" E's are those that typically express animate motion of "self-induced change including a number of run-of-the-mill unaccusative verbs", such as sizum 'sink' and karam 'entwine'. ${ }^{19}$ Aspectually, those R's are [-state, + durative, -telic].
a. Asagao no turu-ga ikegaki-ni karan-da. morning.glory 's vine-NOM hedge-to entwine-PAST 'The morning glory vine entwined around the hedge.'
b. Sue-ga asagao no turu-o ikegaki-ni karam-E-ta. S-NOM morning.glory 's vine-ACC hedge-to entwine-E-PAST 'Sue made the morning glory vine entwine around the hedge.'

Unaccusative R's are inherently subcategorized with an internal argument (IA), and call for no external argument (EA). I suggest that, in the structural context of the [R-E] of such an $\mathrm{R}, v$ suffix $E^{*}$ with its [+ Resulant] feature has an effect of assigning [+ ACC] to that IA, a consequence of which is that the IA (e.g., asagoa no turu 'morning glory vine' in (37b)) needs no longer raise to the Spec of TP position to receive the nominative case, the EA (e.g., Sue) being introduced independently as the volitional agent. (37b) is structurally represented as follows:

$$
\left.\left.\left.\left[{ }_{\mathrm{TP}} \text { Sue }_{\mathrm{i} \ldots}\left[{ }_{\nu \mathrm{P}} t_{\mathrm{i} \ldots[\mathrm{VP}} \text { asagao no turu }\left(t_{\mathrm{j}}\right)\right]\right]_{\mathrm{v}}<\operatorname{karam}_{\mathrm{j}}, E^{*}>\right]\right]\right]
$$

Here, karam 'entwine' internally pair-Merges (Epstein et al. 2016: 98) to suffix $E^{*},\left\{v^{*},<\right.$ karam, $E^{*}>$ \}, to create a " $\mathrm{X}^{0}$-level amalgam." Aspectually, this $\left[\left[_{\text {intr }} \mathrm{R}\right]-E^{*}\right]_{\mathrm{tr}}$ is $[$-state, +durative, + telic] (i,e., "Accomplishment"). The $E$ attachment thus "transitivizes" an R, rendering the EA of the $\left[\left[_{\text {intr }} R\right]-E^{*}\right]_{\text {tr }}$ to be a volitive NP.

Let me note that the discussion so far is consonant with Jacobsen's $(1992,2016)$ "semantic markedness" thesis, the basic guideline of which may be stated as follows:

$$
\begin{aligned}
& \text { Semantic Markedness thesis: } \\
& \text { "when two related linguistic forms co-exist, one relatively more marked than } \\
& \text { the other, there will occur a corresponding division of labor in the meaning } \\
& \text { expressed by the two forms, with the marked form reserved for expressing a more } \\
& \text { "extraordinary" state of affairs than the unmarked forms" (Jacobsen 1992: 12). }
\end{aligned}
$$

Since "it is commonplace in human experience for entities possessing organic or other complex functions to lose those functions spontaneously with the passing of time, without the influence of external force," the Semantic Markedness thesis predicts that the R's that belong to Type (1A) would participate in the "causative" $\{\varnothing / E\}$ pattern (Jacobsen 2016: 28).

19 Jacobsen gives the following as typical examples of "self-induced change and bodily pain" verbs: $a k$ 'open', dok 'get out of the way', hus 'lie', itam 'hurt', kagam 'bend (one's back)', kurusim 'suffer', muk 'face toward', narab 'line up', sodat 'grow', susum 'advance', tat 'stand', tizim 'shrink', ukab 'float'. R karam 'entwine' is not listed in Jacobsen's list but should naturally belong to this class. 


\subsection{Psych-verbs}

A group of psych-verb constructions belonging to Type (1A) $\mathrm{R}-\{\varnothing / E\}$ display a backward reflexivization phenomenon, as pointed out by Hasegawa (see 2001: 23-24; cf. H's (59)).

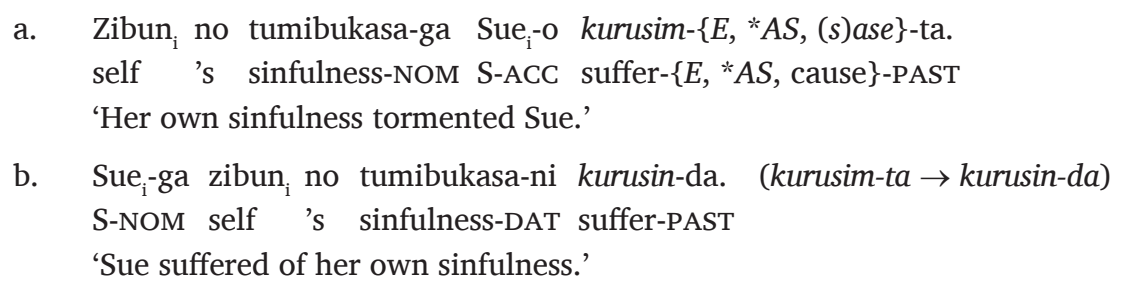

Hasegawa claims, and I concur, that the nominative subject in example (40a) "is not an external argument but is derived from inside VP" (p. 22). Supportive evidence for it is the binding phenomenon. In (40a), the antecedent Sue does not c-command the reflexive zibun 'self'. This apparent puzzle disappears if we assume that (40a) is structurally represented as in (41), in which case the antecedent Sue does c-command the trace of zibun, and we also assume that the internal pair-Merge of R kurusim 'suffer' to suffix $E$ allows [R-E] to assign the accusative case to the IA Sue.

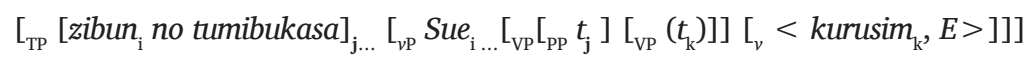

The fact that R-E can participate in backward reflexivization in a fashion parallel to the periphrastic causative (s)ase as in (40a) shows, once again, the "in-between voice" status (Noda 1991: 214) of the Japanese TrAlt system. ${ }^{20}$

\subsection{E attachment to unergative R's}

We have seen that the [ + Resultant] feature of $v$ suffix $E$ attached to an unaccusative R has an effect of assigning [ + ACC] to its internal argument (IA). The unergative R subcategorized with no IA precipitates no such operation. Aspectually, the unergative R's are [-state, + durative] with the telic feature unspecified. The $E$ attachment to such an $\mathrm{R}$ renders the resulting $\left[[R]_{\text {intr }}-E\right]_{\text {intr }}$ construct to be $[-$-state, + durative, + telic], but, without the presence of IA, $E$ fails to act as $v^{*}$. Hence, the [+Resultant] feature associated with $E$ functions only to highlight a resultative sense of the eventuality expressed by the co-occurring $\mathrm{R}$ (recall the discussions in Sections 6.1 and 6.2). The structural representation of (33b) (Suga 1980: 35, (34B)), repeated here as (42a), is (42b).

20 The R's that express psychological or physical sensations like kurusim 'suffer, be.tormented' in (40) all end with $m$, a verbalizing formative that was more productive in pre-historic times. Let me represent it as kurusi-m in (i) and (iv) below to reflect this historical fact, considering $m$ as "verbalizer," representing it as non-italicized "v". There are in fact similar formatives, $k u$ and $s a$, as shown in (ii) and (iii), which can likewise be termed as "adjectivizer" and "nominalizer" respectively. (In Modern Standard Japanese, "adjectivizer" ku followed directly by the present tense, i.e., kurusi-ku-PRES, surfaces as kurusi-i.)

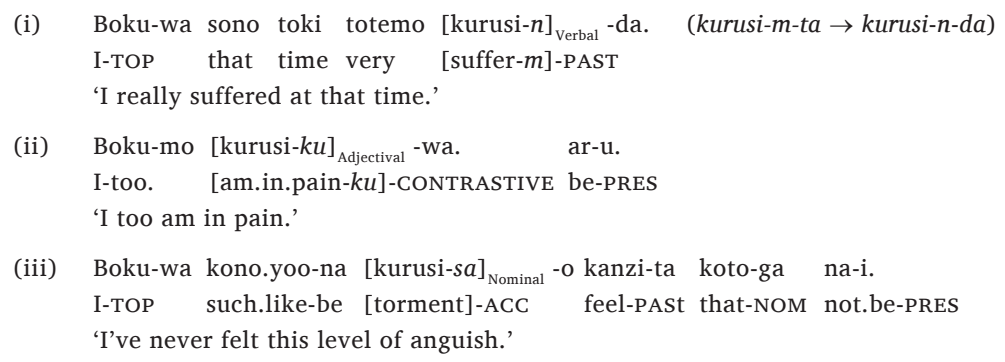

I suggest that these "v's" - that is, "verbalizer" $m$, "adjectivizer" $k u$, and "nominalizer" sa - occasion a case of "external pair-Merge" (briefly mentioned in footnote 10) of "two separate objects," R and v, instantiating what Epstein et al. (2016: 98) call "a morphological operation in the sense that it creates an ' $\mathrm{X}^{0}$-level' amalgam "presyntactically"” (unlike "the $\mathrm{X}^{0}$ amalgams created by internal pair-Merge, i.e. syntactic internal pair-Merge" of R to $v$ ).

(iv) $\quad\left[_{\mathrm{VP}}[\mathrm{PP}\right.$ zibun no tumibukasa-ni $]\left[_{\mathrm{VP}}\left[\left[_{\mathrm{v}}<k u r u s i, m>\right]\right]\right]$

In (ii), R kurusi 'anguish, suffer' - underspecified for verbal, adjectival, and nominal categories - externally pair-Merges to verbalizer $m$ to constitute verbal $\mathrm{R}$, a morphological operation creating an $\mathrm{X}^{0}$-level' amalgam presyntactically. 
a. Kimitu-ga teki-ni mor-E-ta. secret-NOM enemy-to leak-E-PAST

'The secret leaked out to the enemy.'

b. $\quad\left[_{\mathrm{TP}}\right.$ kimitu $\ldots\left[_{v \mathrm{P}} \ldots{ }_{\mathrm{VP}}[\mathrm{PP}\right.$ teki-ni $\left.\left.\left.\left.]\left(t_{\mathrm{i}}\right)\right]\right]\left[\mathrm{g}_{v}<\operatorname{mor}_{\mathrm{i}}, E>\right]\right]\right]$

\subsection{E-attachment to accomplishment R's}

One outstanding characteristic of the R's that co-occur with "intransitivizing" $E$ of Type (1B) $\{E / \varnothing\}$, as Jacobsen (1992: 77) puts it, is that they are predominantly "verbs of destruction and violence" that involve a sudden change of state. ${ }^{21}$ An example of such an R is or 'break': ${ }^{22}$
a. Yuube no taihuu-ga
ki no eda-o
ot-ta.
$($ or-ta $\rightarrow$ ot-ta $)$ last.night 's typhoon-NOM tree 's branch-ACC break-PAST
'Last night's typhoon broke tree branches.'
b. Taihuu-de ki no eda-ga or-E-ta. typhoon-by tree 's branch-NOM break-E-PAST
'A tree branch broke from a typhoon.'

Aspectually, such an "accomplishment" $\mathrm{R}$ is ([-state, + durative, + telic]). Smith (1997: 246) states: "Accomplishments may consist of a finite number of repetitions of an event, indicated with a cardinal or other adverbial. The final endpoint of the last subevent is the final endpoint of the events." I maintain that it is with this sense of "the final endpoint of the last subevent" that the $E$ represents the final endpoint of that eventuality. The same point can be made with yak 'burn' of Type (1B) $\{E / \varnothing\}$ occurring as yak-E, in which the $E$ expresses the final endpoint of the burning event "that results in the disintegration or loss of an entity" (Jacobsen 2016: 26). In terms of Jacobsen's Semantic Markedness thesis, the Type (1B) pairs exhibit the anticausative pattern $\{\varnothing / E\}$ expected "with the events of disintegration." For solid entities to spontaneously disintegrate into parts (regardless of any function the entities might or might not have) "is clearly less common" (Jacobsen 1992: 27).

\subsection{Unified lexico-semantic property of $E$}

Based on the foregoing discussions, I propose a unified account of $v$ suffix $E$, as follows:

Lexico-semantic property of $E$, the unified account:

(i) The $v$ suffix $E$ is associated with [+ Resultant] feature (Section 6.1);

(ii) Attached to an unergative $\mathrm{R}$ such as mor 'leak' with no IA, the [+ Resultant] feature of $E$ in the construct $\left[[R]_{\text {intr }} E\right]_{\text {intr }}$ highlights a sense of resultant state of the event represented by the R's (Section 6.5);

(iii) Attached to an unaccusative R subcategorized with an IA in the $\left[[R]_{\text {intr }} E\right]$, the [+ Resultant] feature of $E^{*}$ renders the construct $\left[[R]_{\text {intr }} E^{*}\right]$ to be transitive $\left[[R]_{\text {intr }} E^{*}\right]_{\text {tr }}$ with ability to assign accusative case to the IA, concurrently requiring the EA to be volitive NP (Section 6.3, (36); Section 5.2).

(iv) Attached to an "accomplishment" R [-state, + durative, + telic] expressing typically destruction and violence, the [+Resultant] feature of $E$ represents the final endpoint of the last subevent represented by that R. Hence, the $E$ of Type (1B) $(\{E / \varnothing\})$ is no longer "transitivizing" (Section 6.5); and

(v) Due to Marantz's No vacuous affixation principle (30), the property of the [ + Resultant] feature associated with $E$ as characterized in (36) is nullified, insofar as the issue of transitivity is concerned, if it is paired with $A R$ as in Type (1C) $\{A R / E\}$ or with $A S$ in Type (1D) $\{E / A S\}$.

21 Jacobsen gives the following R's as typical examples of “destruction and violence” Type (1B) $\{E / \varnothing\}$ R's: kir 'cut', kudak 'smash', muk 'peel', nuk 'pull', or 'break (a stick)', sak 'tear', war 'break (an egg)', yabur 'tear, break', yak 'burn'. Jacobsen (2016: 27-28) calls our attention to "the correlations between formal and semantic markedness" of this kind being "strongly confirmed across other languages as well," referring to such works as Haspelmath (1993) and Comrie (2006).

22 Matsumoto (2016c: 71) notes an interesting phonological fact that causative "stems" (our "R's") "ending in /r/ (and also $/ \mathrm{k} /$ ) all select - $e$ for decausativization" (as in Type (1B) $\{E / \varnothing\}$ ) while Type $(1 \mathrm{~A})\{\varnothing / E\}$ ) "causativizing $-e$ " (as in ak-e 'open') is "disfavored for $/ \mathrm{r} /$-ending base verb. He hypothesizes: "It appears that causativizing $-e$ is avoided for noncausative stems ending in $/ \mathrm{r} /$ since the addition of $-e$ for $/ \mathrm{r} /$ base stems is reserved for decausativization." 


\section{Derivational directionality}

At the end of Section 4.2, I raised the question concerning Type (1C) $\{A R / E\}$ as to why the derivational directionality given in (45) below is the norm, as evidenced by Nishio's (1954) diachronic study, in creating a new R- $v$ formation to complete the Type (1C) $\{A R / E\}$ pattern even though the other way around as stated in (46) is possible (see fn. 3).

$$
\begin{aligned}
& {\left[[\mathrm{R}]_{\mathrm{tr}}-A R\right]_{\mathrm{intr}} \leftarrow\left[[\mathrm{R}]_{\mathrm{tr}}-E\right]_{\mathrm{tr}}} \\
& {\left[[\mathrm{R}]_{\mathrm{tr}}-A R\right]_{\mathrm{intr}} \rightarrow\left[[\mathrm{R}]_{\mathrm{tr}}-E\right]_{\mathrm{tr}}}
\end{aligned}
$$

In this section, I address this question.

Narrog (2016: 281) states unequivocally that equipollent pairs like Type (1C) $\{A R / E\}$ "should exhibit no specific directionality of derivation." I would argue, however, that the derivational directionality is a key factor if we are to account for Nishio's discovery.

I suggest that the key to unlock the puzzle is the peculiar property of $v$ suffix $E$ specified in the root class identification algorithm (31), repeated here as (47).

$$
\text { If } \mathrm{R}+E \text { is presented, then R-category }=\mathrm{R}_{\text {intr }} \text { or } \mathrm{R}_{\text {tr }} \text {. }
$$

The $E$ in Type (1C) $\{A R / E\}$ is thus inert with respect to transitivity. Consider what this means. Given (47), it follows that the relevant equation purely from the transitivity point of view may be restated as in (48):

$$
\left[[R]_{\mathrm{tr}}-E\right]_{\mathrm{tr}}=[\mathrm{R}]_{\mathrm{tr}} \text {. }
$$

Critically, it also follows from this that (45) and (46) may likewise be reformulated as (49) and (50) respectively:

$$
\begin{aligned}
& {\left[[\mathrm{R}]_{\mathrm{tr}}-A R\right]_{\mathrm{intr}} \leftarrow[\mathrm{R}]_{\mathrm{tr}}} \\
& {\left[[\mathrm{R}]_{\mathrm{tr}}-A R\right]_{\mathrm{intr}} \rightarrow[\mathrm{R}]_{\mathrm{tr}}}
\end{aligned}
$$

Recall that in Section 3.2, we have shown that $A R$ 's in the Type (1C) $\{A R / E\}$ pattern are lexical passives, and that lexical passivization is an established grammatical rule active in the context of Japanese TrAlt. We have also seen in Section 4.1 that the passive-like force associated with lexical passive $A R$ can even contribute to the substandard creation of the E-AR constructs where the R's are those that do not participate in TrAlt. ${ }^{23}$

So, then, we have our answer to the derivational directionality question raised above: (49) represents the established grammatical rule of lexical passivization; (50), on the other hand, represents no known grammatical rule.

\section{Mechanisms for productivity}

So far, I have aimed to explicate the workings of TrAlt in Japanese, using the theoretical apparatus adopted in the Strong Minimalist thesis (Chomsky 2013; 2015; and especially Epstein et al. 2016: 98): the merger of two categories of constituents, an $\mathrm{R}$ and a $v$ suffix ( $E, A R$, or $A S$ ) is a syntactic operation deriving an " $\mathrm{X}^{0}$-level' amalgam created by internal pair-Merge (i.e. syntactic internal pair-Merge of R to $v$ )." I subscribe to Noda's (1991: 214) view that the defining characteristic of Japanese TrAlt system is its "in-between voice" quality

23 A question may be raised concerning how Jacobsen's Semantic Markedness thesis would bear upon this question. Jacobsen (1992: 80) seems somewhat uncertain about the equipollence case such as Type (1C) $\{A R / E\}$ :

a considerable number of pairs in this class have intransitive members glossed in English as passives, such as kimaru/kimeru 'be decided/decide', mitukaru/mitukeru 'be found/find', and tasukaru/tasukeru 'be helped/help'. The English morphology in these examples clearly reflects a sense that the intransitive use of verbs such as decide, find, and help is less normal (more marked) than their transitive use.

It is not clear, however, in what way the Semantic Markedness principle contributes to the explanation of directionality as to why " $\left[[R]_{\mathrm{tr}}-A R\right]_{\text {intr }}$ " is more marked than " $\left[[R]_{\mathrm{tr}}-E\right]_{\mathrm{tr}}$ " in the context of Japanese TrAlt. 
operating between two spheres, namely, the truly idiosyncratic lexical formation expressing voice distinction AND the common syntactic operation involving direct passive ( $r$ )are and periphrastic causative (s)ase. This "in-between voice" characteristic manifests in a seemingly contradictory manner within the TrAlt system in that, on one hand, which suffix a given $\mathrm{R}$ takes is "not predictable" (Hasegawa 2001: 2) but, on the other, the TrAlt also allows quite robust new R-AR formations ("new" in the sense that the given R- $v$ constructs were not registered in any relevant dictionaries earlier).

Following Nishio's (1954) diachronic study on the new R-AR creation, this paper has aimed to delineate the nature of the productivity mechanism in engendering new R-AR formations in synchronic terms. What we have found is that, synchronically, the major driving force for new word creation is not "analogy" as assumed by Nishio. "Analogy" may open a path for the derivational directionality $(46) /(50)$ on individual bases as in "[[tati.ag $\left.]_{\mathrm{tr}}-A R\right]_{\text {intr }}$ 'get up' ${ }^{R}\left[[\text { tati.ag }]_{\mathrm{tr}}-E\right]_{\mathrm{tr}}$ 'start up' (see fn. 3). In general terms, though, what functions does analogy play in the system of Japanese TrAlt? The function of analogy in this sense is to identify a possible slot (i.e., either intransitive, transitive, or ditransitive, in a manner reminiscent to PDS as envisioned by Miyagawa (1980; 1984; see our Section 5.1) in the context of TrAlt that can be filled by one of the three transitivity $v$ suffixes $A R, E$, and $A S$, in order to complete a doublet pair in accordance to the patterns represented in (1).

As to what makes the mechanisms for productivity work, there is a unique set of functions associated with two $v$ suffixes in particular, $A R$ and $E$, interacting not only with their host R's but also with each other. Suffix $A R$ with its [-ACC] feature may function as lexical passive in a manner significantly similar to direct passive (r)are, as discussed in Sections 3 and 4. Suffix $E$ with its [+Resultant] feature interacts with its host R's lexico-semantic properties in a complex but definable manner, as discussed in detail in Section 6. Suffix E, furthermore, with its peculiar properties as articulated in (47) and (48), contributes to the proper setting of derivational directionality involved in the new R-AR creation in the context of the Type (1C) $\{A R / E\}$ pattern, as we have just seen in Section 7.

The mechanisms of productivity operative in the context of Japanese TrAlt are thus built on, and sustained by, such a set of functions associated with the two suffixes, $A R$ and $E$, interacting with each other, and working collectively, as a driving force in creating new word formation in a clearly definable manner.

\section{Abbreviations}

ACC $=$ accusative case, DAT $=$ dative case, fn. $=$ footnote, IMP $=$ imperative, intr $=$ intransitive, $\mathrm{NOM}=$ nominative case, $\mathrm{PAST}=$ past tense, $\mathrm{PP}=$ postposition phrase, $\mathrm{PRES}=$ present tense, $\mathrm{Q}=$ question particle, $\mathrm{TOP}=$ topic marker, $\mathrm{tr}=$ transitive, TrAlt $=$ transitivity alternation.

\section{Acknowledgements}

I wish to express my profound gratitude to the anonymous reviewers who commented at great length on earlier versions of this paper, making extremely useful suggestions for improvement. I would also like to acknowledge my indebtedness to Hideo Fujii. In some sense this paper is an extension of Kitagawa \& Fujii 1999. Finally, I want to say my heart-felt thanks to Mary M. Kitagawa, whose help brought this paper, and all of my published papers, to final drafts.

\section{Competing interests}

The author has no competing interests to declare.

\section{Author affiliation}

Chisato Kitagawa (iD orcid.org/0000-0001-9148-4597

University of Massachusetts Amherst, US 


\section{References}

Alexiadou, Artemis, Elena Anagnostopoulou \& Florian Schäfer. 2015. External Arguments in Transitivity Alternation (Oxford Studies in Theoretical Linguistics). Oxford: Oxford University Press. DOI: https:// doi.org/10.1093/acprof:oso/9780199571949.001.0001

Arad, Maya. 1998. VP-structure and the syntax-lexicon interface. London: University College dissertation.

Chomsky, Noam. 1995. The Minimalist Program. Cambridge, MA: MIT Press.

Chomsky, Noam. 2013. Problems of projection. Lingua 130. 33-49. DOI: https://doi.org/10.1016/j. lingua.2012.12.003

Chomsky, Noam. 2015. Problems of projection: Extensions. In Elisa Di Domenico, Cornelia Hamann \& Simona Matteini (eds.), Structures, Strategies and Beyond - Studies in Honour of Adriana Belletti, 3-16. Amsterdam \& Philadelphia: John Benjamins. DOI: https://doi.org/10.1075/la.223.01cho

Comrie, Bernard. 2006. Transitivity pairs, markedness, and diachronic stability. Linguistics 44(2). 303318. DOI: https://doi.org/10.1515/LING.2006.011

Epstein, Samuel E., Hisatsugu Kitahara \& Daniel Seely. 2016. Phase cancellation by external pair-merge of heads. The Linguistic Review 33(1). 87-102. DOI: https://doi.org/10.1515/ttr-2015-0015

Frellesvig, Bjarke \& John Whitman. 2016. The historical source of the bigrade transitivity alternations in Japanese. In Taro Kageyama \& Wesley M. Jacobsen (eds), Transitivity and Valency Alternations. Studies on Japanese and Beyond, 389-310. De Gruyster Mouton. DOI: https://doi. org/10.1515/9783110477153

Genee, Inge. 2016. Blackfoot causative formation between lexicon and grammar. Linguistics 54(5). 10551100. DOI: $h$ ttps://doi.org/10.1515/ling-2016-0026

Hasegawa, Nobuko. 2001. Causatives and the role of $v$ : agent, causer, and experiencer. In Kazuko Inoue \& Nobuko Hasegawa (eds.), Linguistics and Interdisciplinary Research: Proceedings of the COE International Symposium, 1-35. Chiba, Japan: Kanda University of International Studies.

Haspelmath, Martin. 1993. More on the typology of inchoative/causative verb alternations. In Bernard Comrie \& Maria Polinsky (eds.), Causatives and Transitivity (Studies in Languge Companion Series 23), 87-111. Amsterdam and Philadelphia: John Benjamins. DOI: https://doi.org/10.1075/ slcs.23.05has

Hayatsu, Emiko. 1989. Yuutsui tadooshi to mutsui tadooshi no chigai-nitsuite - imiteki-na tokuchoo-o chuushin-ni [On the difference between the transitive verbs participating in the transitivity alternation and those not so participating, in particular reference to their semantic distinctions]. Gengo Kenkyuu 95. 231-256. Reprinted in Suga \& Hayatsu (1995: 179-97).

Jacobsen, Wesley M. 1992. The transitive structure of events in Japanese. Tokyo: Kuroshio Shuppan.

Jacobsen, Wesley M. 2016. The semantic basis of Japanese transitive-intransitive derivational patterns. In Taro Kageyama \& Wesley M. Jacobsen (eds.), Transitivity and Valency Alternatives, Studies on Japanese and Beyond, 21-50. Berlin/Boston: Walter de Gruyter. DOI: https://doi.org/10.1515/9783110477153

Kageyama, Taro. 1996. Dooshi imi-ron [Semantics of verbs]. Tokyo: Kuroshio Shuppan.

Kitagawa, Chisato \& Hideo Fujii. 1999. Transitivity alternations in Japanese. In Liina Pylkkanen, Angeliek van Hout \& Heidi Harley (eds.), Papers from the UPenn/MIT Roundtable on the Lexicon (MIT Working Papers in Linguistics, vol. 35), 87-115. Cambridge, MA: MITWPL.

Kuno, Susumu. The Structure of Japanese Language. Cambridge, MA: MIT Press.

Kuroda, S.-Y. 1979. On Japanese passives. In George Bedell, Eichi Kobayashi \& Masatake Muraki (eds.), Explorations in linguisics: Papaers in honor of Kazuko Inoue, 305-347. Tokyo: Kenkyusha.

Lavine, James E. \& Leonard H. Babby. 2019. A new argument for the lexical underspecification of causers. Linguistic Inquiry 50(4). 803-824. DOI: https://doi.org/10.1162/ling_a_00316

Levin, Beth 7 Malka Rappaport Hovav. 1995. Unaccusativity: At the syntax - lexical Semantics interface. Cambridge, MA: MIT Press.

Mabuchi, Kazuo. 1999. Kodai Nihongo no sugata [Old Japanese and its grammar]. Tokyo: Musashino Shoten.

Marantz, Alec P. 1997. No escape from syntax: Don't try morphological analysis in the privacy of your own lexicon. University of Pennsylvania Working Papers in Linguistics 4(2). 201-225.

Marantz, Alec P. 2013. Locality domains for contextual allomorphy across the interfaces. In Ora Matushansky \& Alex Marants (eds.), Distributed morphology today, 98-115. Cambridge, MA: MIT Press. DOI: https://doi.org/10.7551/mitpress/9780262019675.003.0006

Matsumoto, Yo. 2000a. On the crosslinguistic parameterization of causative predicates: implications from Japanese and other languages. In Miriam Butt \& Tracy H. King (eds.), Argument realization, 135-69. Stanford, CA: Center for the Study of Language and Information.

Matsumoto, Yo. 2000b. Causative alternation in English and Japanese: a closer look. (Review article on Taro Kageyama's Dooshi imiron [Semantics of verbs]), English Linguistics 17. 160-192. DOI: https:// doi.org/10.9793/elsj1984.17.160

Matsumoto, Yo. 2000c. 'Osowar'/'Osieru' nado no tadoosi/nizyuu tadoosi pea no imiteki seisitu 
[Semantic properties of transitive/ditransitive pairs like osowar- $u$ 'learn' and osie-ru 'teach'], In Susumu Yamada (ed.), Kunihiro Tetsuya-kyoozyu koki-kinen ronbunsyuu [Collected papers presented to Professor Tetsuya Kunihiro on his seventieth birthday], 79-95. Tokyo: Hitsuji Shobo.

Matsumoto, Yo. 2016a. List of core causativity pairs in Japanese (a revision of Jacobsen 1992), Appendix A. In Taro Kageyama \& Wesley M. Jacobsen (eds.) (2016: 479-488).

Matsumoto, Yo. 2016b. List of additional causativity pairs in Japanese (a revision of Jacobsen 1992), Appendix B. In Taro Kageyama \& Wesley M. Jacobsen (eds.) (2016: 489-495).

Matsumoto, Yo. 2016c. Phonological and semantic subregularities in noncausative-causative verb pairs in Japanese. In Taro Kageyama \& Wesley M. Jacobsen (eds.) (2016: 51-88).

Miyagawa, Shigeru. 1980. Complex verbs and the lexicon. Tucson, AZ: University of Arizona dissertation.

Miyagawa, Shigeru. 1984. Blocking and the Japanese causatives. Lingua 64. 177-207. DOI: https://doi. org/10.1016/0024-3841(84)90016-0

Miyagawa, Shigeru. 1998. (S)ase as an Elsewhere causative and the syntactic nature of words. Journal of Japanese Linguistics 16. 67-110. DOI: https://doi.org/10.1515/jjl-1998-0105

Miyaji, Kooichi. 1985. Aru-gata dooshi no shosoo - Sakka no hyoogen-o chuushin to shite [How the ar-u type verbs are actually used, in particular reference to literary authors' practices]. Tokyo: Oofuusha.

Motoori, Haruniwa. 1828. Kotoba no kayoiji [Words and their functions]. Reprinted in Benseisha Bunko $25 \cdot 26,1977$.

Muñoz, Carmen P. 2016. Bound lexical formatives: lexicon, grammar or somewhere in between. An FDG perspective. Linguistics 54(5). 1017-1053. DOI: https://doi.org/10.1515/ling-2016-0023

Narrog, Heiko. 2016. Japanese transitivity pairs through time - a historical and typological perspective. In Taro Kageyama \& Wesley M. Jacobsen (eds.) (2016), 241-310.

Nishio, Toraya. 1954. Dooshi no hasei-nituite [On the derivation of new verbs]. Kokugogaku [Studies in Japanese language] 17. 105-117. Reprinted in Suga \& Hayatsu 1995: 41-56.

Noda, Hisashi. 1961. Bunpooteki-na VOICE to goiteki-na VOICE no kankei [On the relationship between grammatical voice and lexical voice]. In Yoshio Nida (ed.), Nihongo no voice to tadoosei [Voice and transitivity in Japanese], 211-232. Tokyo: Kuroshio Shuppan.

Okutsu, Keiichirou. 1967. Jidoo-ka, tadoo-ka oyobi ryookyokuka tenkei [Intransitivization, transitivization, and transitivity change]. Kokugogaku 70. Reprinted in Suga \& Hayatsu (1995: 67-81).

Perlmutter, David M. 1978. Impersonal passives and the unaccusative hypothesis. Proceedings of the Annual Meeting of the Berkeley Linguistics Society 38. 157-189. Published for BLS by the Linguistic Soceity of America. DOI: https://doi.org/10.3765/bls.v4i0.2198

Poppe, Nicholas. 1965. Introduction to Altaic Linguistics. Wiesbaden: Otto Harrassowitz.

Pylkkänen, Liina. 2008. Introducing Arguments. Linguistic Inquiry Monograph 49. Cambridge: MIT Press. DOI: https://doi.org/10.7551/mitpress/9780262162548.001.0001

Robbeets, Martine. 2007. The causative-passive in the Trans-Eurasian languages. Turkic langagues 11. 253-278.

Robbeets, Martine. 2010. Trans-Eurasian: Can verbal morphology end the controversy? In Lars Johanson \& Martine Robbeets (eds.), Verbal morphology and the historical comparison of the Transeurasian languages, 81-114. Wiesbaden: Harrassowitz.

Sakuma, Kanae. 1936. Gendai Nihongo no hyoogen to gohoo [Grammat and discourse In Modern Standard Japanese]. Tokyo: Kooseisha-Kooseikaku.

Shibatani, Masayoshi. 1973. Semantics of Japanese causativization. Foundations of Language 9. $327-373$.

Shimada, Masahiko. 1979. Kokugo-niokeru Zidoosi to Tadoosi [Intransitive and Transitive Verbs in Japanese]. Tokyo: Meiji Shoin.

Smith, Carlota S. 1997. The Parameter of Aspect (Second Edition). Dordrecht, Boston, London: Kluwer Academic Publishers.

Suga, Kazuyoshi. 1980. Heizon-suru jidooshi/tadooshi no imi [Semantic analysis of co-existing intransitive and transitive verbs involving the same roots]. Kokugogaku 120. 31-41.

Volpe, Mark Joseph. 2005. Japanese Morphology and its theoretical consequence: Derivational morphology in Distributed Morphology. Stony Brook, NY: Stony Brook University dissertation.

Whitman, John. 2008. The bigrade conjugation and stem shape in Pre-Old Japanese. In Bjarke Frellesvig \& John Whitman (eds.), Proto-Japanese: Issues and Prospects, 159-173. Amsterdam: John Benjamins. DOI: https://doi.org/10.1075/cilt.294.13whi 
Glossa: a journal of general linguistics

DOI: 10.5334 /gjgl.1304

TO CITE THIS ARTICLE: Kitagawa, Chisato. 2021

Mechanisms of productivity in word formation: Transitivity alternations in Japanese. Glossa: a journal of general linguistics 6(1): 69. 1-24. DOI: https://doi.org/10.5334/ gjgl.1304

Submitted: 11 May 2020 Accepted: 10 November 2020 Published: 21 May 2021

COPYRIGHT:

(c) 2021 The Author(s). This is an open-access article distributed under the terms of the Creative Commons Attribution 4.0 International License (CC-BY 4.0), which permits unrestricted use, distribution, and reproduction in any medium, provided the original author and source are credited. See http:// creativecommons.org/ licenses/by/4.0/.

Glossa: a journal of general linguistics is a peer-reviewed open access journal published by Ubiquity Press. 